\title{
Study of the Effect of Administration of Citalopram on the Liver of the Pregnant Albino Rats and the Liver of their Offspring
}

\author{
SHIMAA R. ABD EL-MOHSEN, M.Sc.; FATMAH H.M.K. ISMAEIL, M.D. and \\ AMANY F. MOHAMED, M.D. \\ The Department of Anatomy and Embryology, Faculty of Medicine for Girls, Al-Azhar University, Cairo, Eygpt
}

\begin{abstract}
Background: Depression and anxiety are common public health problems. Citalopram is the first line of treatment for depression among SSRIs with high potency and selectivity for serotonin uptake. Pregnancy appears to increase the risk of anxiety by $10-30 \%$ of pregnant women. Women previously known with depressive disorder have an increased risk of depression in connection with pregnancy. The liver is a primary target of adverse drug reactions because it is the predominant site for the biotransformation and metabolism of the drugs. Aim of the study: The aim of the study was to evaluate the effect of administration of citalopram on the liver of the pregnant albino rats and the liver of their offspring.
\end{abstract}

Material and Methods: Forty pregnant albino rats were chosen for this study. They were divided into two equal groups, each group contained twenty pregnant albino rats. Each group was subdivided into two equal subgroups and each subgroup contained ten pregnant albino rats: Group I (control group): Each pregnant albino rat was already given by a gastric gavage $0.18 \mathrm{ml}$ distilled water daily one week before pregnancy. This group was divided equally into 2 sub-groups: Subgroup IA: Each pregnant albino rat was given by a gastric gavage $0.18 \mathrm{ml}$ distilled water daily during pregnancy. Subgroup IB: Each pregnant albino rat was given by a gastric gavage $0.18 \mathrm{ml}$ distilled water daily during pregnancy and continued daily for 2 weeks after delivery with the same dose. Group II (Citalopram treated group): Each pregnant albino rat was given by a gastric gavage $0.18 \mathrm{ml}$ distilled water containing $0.36 \mathrm{mg}$ citalopram daily one week before pregnancy. This group was divided equally into 2 sub-groups: Subgroup IIA: Each pregnant albino rat also was given by a gastric gavage $0.18 \mathrm{ml}$ distilled water containing $0.36 \mathrm{mg}$ citalopram daily during pregnancy. Subgroup IIB: Each pregnant albino rat also was given by a gastric gavage $0.18 \mathrm{ml}$ distilled water containing $0.36 \mathrm{mg}$ citalopram daily during pregnancy and continued 2 weeks after delivery. At the end of the experimental period, the albino rat mothers and their offspring were collected on the 1 st day (subgroups IA and IIA) and fifteenth days after delivery (subgroups IB and IIB). Biochemical study was done for all albino rat mothers before liver dissection by taken blood samples to measure the levels of Aspartate Amino Transferase (AST), Alanine Aminotransferase (ALT) and

Correspondence to: Dr. Shimaa R. Abd El-Mohsen, The Department of Anatomy and Embryology, Faculty of Medicine for Girls, Al-Azhar University, Cairo, Eygpt
Gamma Glutamyl Transpeptidase (GGT) in the serum followed by statistical analysis of the data using unpaired student's $t$ test. Paraffin sections for albino rat mothers and their offspring were prepared to be stained with $\mathrm{H} \& \mathrm{E}$, Masson's trichrome and Gordon and sweet's stains for light microscopic study. Specimens of the liver were also prepared for electron microscopic study. The semithin sections were cut and stained with toluidine blue and examined by light microscope. The ultrathin sections were cut and examined using a transmission electron microscope.

Results: Administration of citalopram led to a significant elevation in the liver enzymes of the albino rat mothers. Also, citalopram caused cellular degeneration, necrosis, apoptosis, congestion of the hepatic veins and the portal veins in the hepatic tissue of the albino rat mothers and their offspring.

Conclusion: Citalopram caused degenerative changes in the liver of the albino rat mothers and their offspring when it was administered before and during pregnancy and after delivery.

Key Words: Citalopram - Pregnant - Albino rats - Liver Offspring.

\section{Introduction}

DEPRESSION and anxiety are common public health problems that affect $5-10 \%$ of the world population $[1,2]$. Epidemiological studies show that depression and anxiety often occur during the reproductive years that is age between 20-60 [2] Pregnancy is one of the happiest times of a woman's life but for many women, this is a time of confusion, fear, stress and even depression as approximately $50 \%$ of all pregnancies are unplanned. According to the American Congress of Obstetricians and Gynecologists (ACOG), between 14-23\% of women fight with some symptoms of depression during pregnancy. Pregnancy appear to increase the risk of anxiety by $10-30 \%$ of pregnant women. Women previously known with depressive disorder have an increased risk of depression in connection with pregnancy. About half of these conditions will continue after the birth of the child [3] 
Selective Serotonin Reuptake Inhibitors (SSRIs) are the pharmacological treatment of choice for depression, anxiety and obsessive-compulsive disorder. These drugs are specifically recommended for the treatment of these disorders during pregnancy and lactation [4,5]. Citalopram is the first line of treatment among SSRIs for depression with high potency and selectivity for serotonin uptake $[3,6]$.

The liver is a primary target of adverse drug reactions because it is the predominant site for the biotransformation and metabolism of the drugs. The severity of drug induced liver injury can range from asymptomatic increase in liver enzymes to fulminant hepatic failure and even death [7]. Drug induced liver injury from antidepressant drugs may be irreversible [8]. Citalopram is metabolized extensively by the liver [9]. Citalopram and its metabolite concentrations have been detected in both umbilical cord blood and amniotic fluid in women taking this medication during pregnancy [10]

So, this work aimed to study the effect of administration of citalopram on the liver of the pregnant albino rats and the liver of their offspring.

\section{Material and Methods}

\section{Animals:}

Sixty random bred adult albino rats weighing from 150-200gm were used in this experimental study, forty eight rats were females and twelve rats were males. They were obtained and provided by veterinary care by the Animal House of Faculty of Medicine, Cairo University (from 15 November 2015 to 30 August 2016) according to the guidelines for Animal Research approved by Animal Ethics Committee. They were given balanced diet and water (standard diet pellets-El-Nasr-Company, Abou-Zaabal-Egypt). They were sub-caged in a conventional clean facility at $22-26^{\circ} \mathrm{C}$. Twenty four adult female albino rats were given by a gastric gavage $0.18 \mathrm{ml}$ distilled water daily for one week. The other twenty four adult female albino rats were given by a gastric gavage $0.18 \mathrm{ml}$ distilled water containing $0.36 \mathrm{mg}$ citalopram/rat/daily for one week. All the previous forty eight adult female albino rat groups were allowed for mating by keeping each four adult female albino rats overnight in a cage with a single adult male rat. In the next day, forty four of the adult female rats showed a vaginal plug (getting pregnant) and this day was considered to be the first day of pregnancy ( 23 adult female albino rats that were given distilled water and 21 adult female albino rats that were given citalopram). From the previous pregnant albino rats, forty pregnant albino rats were chosen for this study. Each pregnant albino rat was kept in a separate cage until delivery. The pregnant albino rats were divided into two groups and each group contained twenty pregnant albino rats (20 pregnant albino rats that were given a distilled water and 20 pregnant albino rats that were given citalopram). Each group was subdivided into two subgroups and each subgroup contained ten pregnant albino rats.

\section{Experimental design:}

- Group I (control group): Each pregnant albino rat was already given by a gastric gavage $0.18 \mathrm{ml}$ distilled water daily one week before pregnancy. This group was divided equally into 2 sub-groups:

- Subgroup IA: Each pregnant albino rat was given by a gastric gavage $0.18 \mathrm{ml}$ distilled water daily during pregnancy. These albino rats and their offspring were collected and used for the study on the 1 st day after delivery.

- Subgroup IB: Each pregnant albino rat was given by a gastric gavage $0.18 \mathrm{ml}$ distilled water daily during pregnancy and continued daily for 2 weeks after delivery with the same dose. These female albino rats and their offspring were collected and used for the study on the $15^{\text {th }}$ day after delivery.

- Group II (citalopram treated group): Each pregnant albino rat was already given by a gastric gavage $0.18 \mathrm{ml}$ distilled water containing $0.36 \mathrm{mg}$ citalopram daily one week before pregnancy. This group was divided equally into 2 sub-groups:

- Subgroup IIA: Each pregnant albino rat also was given by a gastric gavage $0.18 \mathrm{ml}$ distilled water containing $0.36 \mathrm{mg}$ citalopram daily during pregnancy. These albino rats and their offspring were collected and used for the study on the 1 st day after delivery.

- Subgroup IIB: Each pregnant albino rat also was given by a gastric gavage $0.18 \mathrm{ml}$ distilled water containing $0.36 \mathrm{mg}$ citalopram daily during pregnancy and continued 2 weeks after delivery. These albino rats and their offspring were collected and used for the study on the $15^{\text {th }}$ day after delivery.

Drug:

- Citalopram is available as an oral tablet, each one is contained $20 \mathrm{mg}$. It is manufactured in Denmark by H.Lundbeck A/S-Copenhagen (Trade name, Cipram). Each tablet was crushed in order to get of powder form. The rat therapeutic dose was prepared daily by dissolving a powder of tablet (containing $20 \mathrm{mg}$ ) in $10 \mathrm{ml}$ of distilled water. Each female albino rat (Group II) was 
given by a gastric gavage a single daily dose of $0.18 \mathrm{ml}$ containing $0.36 \mathrm{mg} /$ day. The average human therapeutic dose of citalopram for adult human weighing $70 \mathrm{~kg}$ is $20 \mathrm{mg} /$ day [11]. The equivalent therapeutic dose for adult albino rat was calculated according to the formula of Paget and Barnes [12]. The formula was used to convert the human therapeutic dose to the rat dose as follow: $20 \mathrm{X} 18 / 1000=0.36 \mathrm{mg}$ per day/rat (weighing from 150-200gm).

\section{Biochemical study:}

The aim of this procedure was to detect the hepatic injury. The blood samples were taken from the retro-orbital vein of the albino rat mothers of all groups, collected into test tubes and transferred to the Biochemistry Department of Faculty of Medicine, Cairo University and the Regional Center for Mycology and Biotechnology, Al-Azhar University. The levels of Aspartate Amino Transferase (AST), Alanine Aminotransferase (ALT) and Gamma Glutamyl Transpeptidase (GGT) in serum were assessed using conventional laboratory methods [13].

\section{Statistical analysis of the biochemical study:}

The results of biochemical study were also collected, tabulated, statistically analyzed and represented graphically using unpaired student's $t$-test which was done for quantitative data of two independent samples [14]. If the degree of probability $(p)$ is more than 0.0500 , the results will be insignificant statistically. The lower the $(p)$ value was $(0.01,0.001,0.0001 \ldots . .$. etc. $)$ the higher the degree of significance.

\section{Microanatomy study:}

Preparation for light microscopic examination:

Collection of the specimens: On 1 st and the $15^{\text {th }}$ days after delivery, the albino rat mothers and their offspring were anaesthetized lightly by diethyl ether inhalation. Their abdominal cavities were exposed by midline incision. The liver specimens were identified in the abdominal cavities and were collected from all groups (mothers and their offspring).

Preparation of serial transverse paraffin sections: The livers of mothers and their offspring were taken immediately, fixed in $10 \%$ formal saline solution for 3 days. The specimens were dehydrated in ascending grades of ethyl alcohol. The specimens were cleared in benzene for 24 hours. The cleared specimens were impregnated in paraffin wax. The paraffin blocks were cut by a rotatory microtome into serial transverse section at (4um) thickness.
Every five successive paraffin sections were placed on an albumenized glass slides [15]. The consecutive slides obtained from each specimen were stained with the following stains: 1- Elrich's hematoxylin and Eosin stain [15,16], 2- Masson's trichrome stain $[15,16]$ and 3- Gordon and sweet's stain [17].

Preparation forsemithin sections and Transmission Electron Microscopy (TEM) [18] :

Special care was taken to obtain the specimens while the rats were still alive under light ether anesthesia, very small pieces of the liver were collected from all studied groups. Specimens were immediately fixed by immersion in cold $5 \%$ glutaraldhyde in $0.1 \mathrm{M}$ sodium cacodylate buffer, $\mathrm{PH}$ 7.3 at $0-4^{\circ} \mathrm{C}$. Then, post fixed with $1 \%$ osmium tetraoxide $\left(\mathrm{OsO}_{4}\right)$, dehydrated and embedded in epoxy resin. The semi thin sections (1 mick) were cut on an LKB ultratome and stained with toluidine blue and examined by light microscope. Ultrathin section (60nm thick) were cut, mounted on cupper grids, and stained with uranyl acetate and lead citrate. The ultrathin sections were examined using a transmission electron microscope (JEOL1010 EX II, Japan) at the Regional Mycology and Biotechnology Center, Al-Azhar University, Cairo, Egypt.

\section{Results}

\section{Biochemical results:}

The following biochemical parameters were done to record the effect of citalopram on the liver function. The level of Aspartate Amino Transferase (AST), Alanine Amino Transferase (ALT) and Gamma Glutamyl Transpeptidase (GGT) enzymes in the serum of the albino rat mothers of all studied subgroups were recorded and statistically analyzed using unpaired student's $t$-test.

I- Statistical analysis as regarded to the mean values and standard deviation of AST, ALT and GGT of the albino rat mothers on the 1ST day after delivery of subgroups IA and IIA using unpaired student's $t$-test revealed that there was highly significant difference in the level of AST, ALT and GGT between subgroups IA and IIA ( $p$-value $<0.001$ ) (Table 1), Graph (1).

II- Statistical analysis as regarded to the mean values of AST, ALT and GGT of the albino rat mothers on the $15^{\text {th }}$ day after delivery of subgroups IB and IIB using unpaired student's $t$-test revealed that there was highly significant difference in the level of AST, ALT and GGT between subgroups BI and BII ( $p$-value <0.001) (Table 2), Graph (2). 


\section{Microanatomy results:}

\section{Group I (control group):}

The light microscopic examination of the sections of the livers of one day old albino rat offspring of the control albino rat mothers (Subgroup IA) showed that the liver formed of irregular groups of hepatocytes around the central veins Fig. (1C). The hepatocytes were separated by an irregular shaped blood sinusoids and numerous hemopoietic cells and islets. Some of the hepatocytes were polyhedral in shape while others appeared with irregular cell boundaries. The hepatocytes had eosinophilic granular cytoplasm and large vesicular basophilic nuclei Figs. (1C,2C). The central veins were nearly rounded in shape, they were lined by irregularly arranged single layer of flat endothelial cells with flat nuclei Fig. (1C). The blood sinusoids were lined with the endothelial cells and von Kupffer cells. The endothelial cells were flat in shape with dark flat nuclei. The von Kupffer cells had large star or stellate shaped appearance or stellate with dark oval nuclei and were anchored in the blood sinusoids Figs. (1C,2C). The hemopoietic cells had intense eosinophilic cytoplasm with deeply stained basophilic nuclei. They were found widely dispersed throughout the liver or arranged as small islets in between the hepatocytes Figs. (1C,2C). The portal tracts formed of a branch of the portal vein, a branch of the hepatic artery and a tributary of the interlobular bile duct Fig. (2C). Masson's trichrome stain showed a faint layer of collagen fibers appeared around the elements of the portal tract. These collagen fibers were also radiated for a short distance along the wall of the blood sinusoids which were adjacent to the portal tract Figs. (3C). Gordon and sweets silver stain showed that the framework of the liver was formed of reticular fibers. These reticular fibers were delicate and distributed around the central vein, in between the hepatocytes and around the elements of the portal tract Figs. (4C). Semi-thin sections revealed that most of the hepatocytes appeared polyhedral in shape with single rounded vesicular nuclei containing one or two nucleoli. Few hepatocytes were irregular in shape. Few hepatocytes were seen with two nuclei. Many hemopoietic cells and islets were seen among the hepatocytes. The von Kupffer cells and the endothelial cells lined the blood sinusoids and red blood corpuscles appeared within the lumen of these blood sinusoids. The von Kupffer cells were large star like cells with dark oval nuclei and the endothelial cells were flat in shape with dark flat nuclei. Ito cells were found facing the sinusoidal surface of hepatocytes, they were perisinusoidal cells containing multiple lipid droplets in their cytoplasm and had irregular nuclei Fig. (5C).

The electron microscopic examination of ultrathin section of the liver of one day old albino rat offspring of the control albino rat mothers (Subgroup IA) revealed that there were two kinds of the hepatocytes in the liver. One was the dark hepatocyte which was electron-dense with many mitochondria. The other one was the light hepatocyte which was electron-lucent with less number of mitochondria Fig. (6C). The nuclei of the hepatocytes were nearly rounded and central or eccentric. They were surrounded by a well demarcated nuclear envelope which was interrupted at various intervals by many nuclear pores. They contained both euchromatin and heterochromatin within the karyoplasm, also contained a nucleolus which appeared sponge like, Figs. (6C,7C). The cytoplasm of the hepatocytes contained many organelles which were the mitochondria, the rough endoplasmic reticulum, and many free ribosomes and also contained cytoplasmic inclusions like the glycogen which were scattered or in clusters Fig. (7C). The plasma membrane of the hepatocytes had basal or sinusoidal surfaces, lateral and canalicular surfaces. The surface of hepatocytes that faced the blood sinusoids were called the sinusoidal surface. Small irregular microvilli were projected from the sinusoidal surface of the hepatocytes into the space of diss which was present between the sinusioidal lining cells and the hepatocytes. The lateral surface lied in between hepatocytes. The intercellular space that constitute the bile canaliculi called canalicular surface. The bile canaliculi appeared with short stubby microvilli of two neighboring hepatocytes Figs. (6C,7C). The blood sinusoids were lined by von Kupffer cells and endothelial cells. The von Kupffer cells contained irregular nuclei which appeared with abundant heterochromatin aggregated on the inner surface of the nuclear envelope and scattered within their karyoplasm. The endothelial cells were flat cells with oval nuclei Fig. (6C).

The light microscopic examination of sections of the livers of 15 days old albino rat offspring of the control albino rat mothers (subgroup IB) showed that the liver became more developed than previous age. The hepatic cords were radiating from the central veins. Each cord was formed of 1-2 rows of hepatocytes. The cords of the hepatocytes were separated by slit like blood sinusoids Fig. (8C). All the hepatocytes became polyhedral in shape Figs. (8C,9C). Masson's trichrome stain showed that the collagen fibers appeared more or less as those of the previous age Figs. (3C,10C). Gordon and sweets silver stain showed that the reticular 
fibers became fine and well radiated from the central vein, in between the hepatic cords and around the elements of the portal tract. The hexagonal hepatic lobules still not well defined yet Fig. (11C). Semi-thin sections revealed that most of the hepatocytes appeared polyhedral in shape with large, rounded, vesicular and central nuclei while few still irregular in shape with eccentric nuclei. The nuclei of the hepatocytes contained one or two nucleoli. The von Kupffer cells and the endothelial cells were similar to those of the previous age Figs. (5C,12C). No haemopoieic cells were in between the hepatocytes Fig. (12C).

The electron microscopic examination of the ultra-thin sections of the liver of 15 days old albino rat offspring of the control albino rat mothers (subgroup IB) revealed that all the hepatocytes became light type and most of them were polyhedral in shape Figs. (13C,14C). The plasma membrane, nuclei, and the cytoplasmic organelles and inclusions were similar to those of the previous age Figs. (6C,7C,13C,14C).

The histological examination of the sections of the livers of albino rat mothers of subgroups IA and IB revealed no difference in their microanatomy results, so their results were pooled together.

The light microscopic examination of sections of the liver of the albino rat mothers (subgroups IA and IB) showed the liver made of regular, radial, branching and anastomosing network of the hepatic cords separated by slit shaped blood sinusoids Figs. (1 5C, 16C). Masson's trichrome stain showed that the amount of collagen fibers around the elements of the portal tract became more than the previous ages Figs. (3C,10C,17C). Gordon and sweets silver stain showed that the framework of the hexagonal hepatic lobules which formed of reticular fibers became well defined. These reticular fibers became more in between the hepatic cords and more condensed around the central vein and around the elements of the portal tract as compared to the previous ages Figs. (4C,11 C,18C). Semithin sections revealed that most of the hepatocytes became large and polyhedral in shape with single large, rounded, vesicular and central while few hepatocytes had two nuclei. Apparently, von Kupffer cells became less in number than seen in the 15 th day old offspring Figs. (12C,19C).

The electron microscopic examination of ultrathin sections of the liver of albino rat mothers (subgroups IA and IB) was similar to the previous age Figs. (6C,7C, 13C, 14C, 20C,21 C) but few nuclei contained intranucleur pseudo inclusion body. Also, the microvilli in the space of Disse became coarse and well developed as compared to the previous ages Figs. (6C,13C,20C). The lateral surface that lied in between the hepatocytes became closely approximated with that of the adjoining hepatocyte by desmosomal junctions Figs. (20C, 21C). The bile canaliculi appeared with short stubby microvilli of two adjacent hepatocytes Figs. (20C, 21C) and the canalicular lumen was sealed by tight junctions known as junctional complex between adjacent hepatocytes Fig. (21C). The lining cells of the blood sinusoids were similar with these of the previous ages Figs. (6C,13C,20C).

\section{Group II (Citalopram treated group):}

The light microscopic examination of serial transverse sections of the liver of one day old albino rat offspring of citalopram treated mothers (subgroup IIA) showed that the irregular groups of hepatocytes became widely separated by dilated blood sinusoids which contained blood cells and lined by flat elongated endothelial cells and von Kupffer cells Figs. (1T,2T). Most of the hepatocytes became with irregular cell boundaries. They had vacuolated cytoplasm and small deeply stained nuclei while others lost their cytoplasm and nuclei forming areas of vacuolated cells Figs. (1T,2T). Some hepatocytes lost their cell boundaries forming a homogenous areas of cytoplasm Figs. (1T,2T). Few polyhedral hepatocytes appeared as those of the control one Figs. $(1 \mathrm{C}, 1 \mathrm{~T}, 2 \mathrm{C}, 2 \mathrm{~T})$. The scattered hemopoietic cells and islets became more numerous within the parenchyma of the liver than those of the control one Figs. (1C,1T,2C,2T). The central vein became irregular in shape and dilated Fig. (1T). The portal tract showed dilatation of the branch of the portal vein which became engorged with blood Figs. (2T). Masson's trichrome stain showed an increase of collagen fibers distribution around the elements of the portal tracts. The collagen fibers also radiated for a short distance along the wall of the blood sinusoids which were adjacent to the portal tract Fig. (3T). Gordon and sweets silver stain showed an apparent increase in the condensation of reticular fibers around the elements of the portal tract as compared to the control one Figs. (4C,4T). Semi-thin sections revealed that most of the hepatocytes had minute rounded vacuoles in their cytoplasm Fig. (5T). Some of their nuclei still rounded, vesicular and central containing one or two nucleoli Fig. (5T). Other nuclei became enlarged and irregular in shape Fig. (5T). Mitotic figures appeared in some hepatocytes Fig. (5T). Many hemopoietic cells and islets were seen among the hepatocytes Fig. (5T). The blood sinusoids became dilated and filled with red blood corpuscles 
Fig. (5T). Von Kupffer cells and endothelial cells lined the blood sinusoids. Ito cells could not be recognized Fig. (5T).

The electron microscopic examination of the ultra-thin sections of the liver of one day old albino rat offspring of citalopram treated albino rat mothers (subgroup IIA) revealed that the hepatocytes became irregular in shape with partial loss of the plasma membrane in small areas Fig. (6T). The nuclei of the hepatocytes either became small with increased their chromatin content, or enlarged. Some nuclei appeared indentated with an irregular nuclear envelope Figs. (6T,7T). Most of the mitochondria became swollen with partial or even complete loss of their matrix and cristae, few of these mitochondria raptured Figs. (6T,7T). The rough endoplasmic reticulum became few as compared to the control one Figs. (7C,7T). The free ribosomes were scattered all over the cytoplasm Fig. (7T). The glycogen granules became less than those of the control one Figs. (7C,7T). Leached lipid droplet was observed Fig. (7T). The microvilli of the space of Diss could not be recognized Fig. (6T). The bile canaliculus hardly recognized Fig. (7T). The blood sinusoids were lined by von Kupffer cells and the endothelial cell. The haemopoietic cells were scattered in between the hepatocytes Fig. (6T).

The light microscopic examination of serial transverse sections of the liver of fifteen days old albino rat offspring of citalopram treated albino rat mothers (subgroup IIB) showed disturbed hepatic architecture. The hepatic cords became distorted around the central veins Fig. (8T). The hepatocytes appeared more affected in the periportal area than in the pericentral area of the hepatic lobules. In the pericentral area, most of the hepatocytes were polyhedral in shape with small vacuoles within their cytoplasm, most of their nuclei were rounded vesicular nuclei and few of them became small deeply stained. In the periportal area, most of the hepatocytes lost their normal polyhedral shape and became with ill defined cell boundaries and massive vacuolated cytoplasm. Most of their nuclei became small deeply stained Figs. (8T,9T). The central veins appeared more or less as the control one Figs. (8C,8T). Most of the blood sinusoids lost their slit like shaped and became with different shapes in the pericentral area while in the periportal area most of them had slit like appearance Figs. (8T,9T). The area of the portal tract showed that the branch of the portal vein became dilated and engorged with the blood. The branch of the hepatic artery became dilated and had thick wall. There were some inflammatory cells which sur- rounded the portal tract Fig. (9T). Masson's trichrome stain showed the collagen fibers distribution were seemed to be more than that of the control one of the same age Figs. (10C,10T). Gordon and sweets silver stain showed that the distribution of fine reticular fibers around the central vein in between the hepatic cords, and around the elements of the portal tract appeared more or less as those of the control one of the same age Figs. (11C,11T). Semi-thin sections revealed that some of the hepatocytes were irregular in shape with vacuolated cytoplasm and small dark nuclei. Some of the hepatocytes still polyhedral in shape with vacuolated cytoplasm and vesicular rounded nuclei with one or two nucleoli. Von Kupffer cells and endothelial cell were similar to those of the control Figs. $(12 \mathrm{C}, 12 \mathrm{~T})$. Red blood corpuscles were within the lumen of the blood sinusoids Fig. (12T).

The electron microscopic examination of the ultra-thin sections of the liver of fifteen days old albino rat offspring of citalopram treated albino rat mothers of subgroup IIB revealed that some of the hepatocytes lost their polyhedral shape and became surrounded by ill-defined plasma membrane Fig. (13T). Some of their nuclei became small eccentric with an increase in their heterochromatin and they were surrounded by discontinued nuclear envelope. This nuclear envelope contained nuclear pores. Few vacuoles appeared in the cytoplasm of the hepatocyte. Some mitochondria became vacuolated with partial loss of their cristae and matrix while some of them became matted together. Some of the matted mitochondria contained vacuoles in their center Fig. (14T). Most of the rough endoplasmic reticulum became dispersed, dilated with apparent increase in their surface ribosomes however the rough endoplasmic reticulum around the nucleus became difficult to be recognized Fig. (14T). Free ribosomes and glycogen within the cytoplasm of the hepatocytes were more or less similar to those of the control of the same age Figs. (14C,14T). Partially leached lipid droplets and lysosomes appeared within the cytoplasm of the hepatocytes Fig. (14T). The bile canaliculi dilated Fig. (1 3T). Microvilli of the space of Diss appeared more or less as those of the control one of the same age Figs. (13C, 13T). The wall of the blood sinusoids contained some collagen fibrils and were lined by von Kupffer cells which had many cytoplasmic vacuoles Fig. (13T).

The light microscopic examination of serial transverse sections of the liver of citalopram treated albino rat mothers of subgroup IIA showed that the hepatic cords became irregularly radiating from 
the central vein Fig. (15T). The hepatocytes showed degenerative changes which were more marked in the pericentral area than in the periportal area. In the pericentral area, most of the hepatocytes lost their polyhedral shaped and some of them became with ill defined cell boundaries. Multiple vacuoles appeared within their cytoplasm. Their nuclei appeared either rounded vesicular or became small and deeply stained. Some hepatocytes became small, their cytoplasm became homogenous with increased eosinophilia and their nuclei became small deeply stained. In the periportal area the same changes were observed but the hepatocytes with homogenous eosinophilic cytoplasm were apparently less than these in the pericentral area Figs. (15T,16T). The central veins became dilated as compared with that of the control one (Figs. 15C,15T). Most of the blood sinusoids appeared dilated and irregularly radiating from the central vein while others appeared had slit like appearance and both were lined by endothelial cells and von Kupffer cells Figs. (15T,16T). The portal tract showed marked dilatation of the branch of the portal vein, the branch of the hepatic artery and the lymphatics while the interlobular bile ductule appeared more or less as the control one Figs. (16C,16T). Masson's trichrome stain showed an increase of the collagen fibers distribution around the elements of the portal tract and in the wall of some blood sinusoids which were adjacent to the portal tract Figs. (17T). Gordon and sweets silver stain showed an increased in the condensation of fine reticular fibers around the central vein and around the elements of the portal tract Fig. (18T). Semi-thin sections revealed that most of the hepatocytes had cytoplasmic vacuolation. Some of the hepatocytes appeared polyhedral in shape with rounded vesicular nuclei containing one or two nucleoli while others appeared irregular in shape with small deeply stained nuclei. Von Kupffer cells and endothelial cells lined the blood sinusoids. Red blood corpuscles were seen within the lumen of the blood sinusoids Fig. (19T).

The electron microscopic examination of the ultra-thin sections of the liver of citalopram treated albino rat mothers of subgroup IIA revealed that the nucleus of the hepatocyte was surrounded by nuclear envelope which contained nuclear pores. They contained more electron dense clumps of heterochromatin on the inner aspect of the nuclear envelope and within the karyoplasm. The heterochromatin surrounding the nucleolus became more electron dense Figs. (20T,21 T). Multiple vacuoles appeared in the cytoplasm of the hepatocytes, few of these vacuoles contained lamellar bodies. There was large vacuolated area of cytoplasm contained lamellar body which contained electron dense material Fig. (21T). The mitochondria appeared more or less as those of the control one Figs. (21C, $21 \mathrm{~T})$. Some of the rough endoplasmic reticulum became scattered in the cytoplasm Fig. (21T). Free ribosomes within the cytoplasm appeared more or less as those of the control one Figs. (21C,21T). The glycogen granules apparently were less than those of the control one Fig. (20C,20T, 21C,21T). The microvilli in the space of Diss could not be recognized Fig. (20T). The bile canaliculus between the two adjacent hepatocytes could not be recognized Fig. (20T). The blood sinusoids were lined by von Kupffer cells which apparently increased in numbers. Some von Kupffer cells had irregular heterochromatic nuclei and contained cytoplasmic vacuoles, phagosomes and primary lysosome in their cytoplasm. Few collagen fibrils were seen in the wall of some blood sinusoids Fig. (20T).

The light microscopic examination of serial transverse sections of the liver of citalopram treated albino rat mothers of subgroup IIB showed that the hepatic architecture was lost with marked degenerative changes all over the parenchyma Fig. (22T). The hepatocytes lost their arrangement into cords and lost their radiation from the central veins Fig. (22T). The hepatocytes showed degenerative changes similar to those in the liver of the citalopram treated mother one day after delivery but most of the hepatocytes became with vacuolated cytoplasm and their nuclei became small, irregular and deeply stained. Few of the hepatocytes lost most of their cytoplasm and their nuclei forming vacuoles containing remnants of cytoplasm Figs. (22T,23T). The central vein appeared markedly dilated with disturbance of its endothelial lining Fig. (22T). All blood sinusoids lost their slit like shape and became irregular and dilated in the pericentral area while in the periportal area most of them still had slit like appearance Fig. (22T,23T). The portal tract showed that the branch of the portal vein became markedly dilated and engorged with blood. The branch of the hepatic artery became dilated and had thick wall. The interlobular bile ductule and lymph vessels appeared more or less as those of the control one Figs. (9C,23T). Masson's trichrome stain showed marked increase in the distribution of the collagen fibers around the elements of the portal tract Fig. (24T). Gordon and sweets silver stain showed loss of the normal arrangement of the hexagonal hepatic lobules with an increased in the condensation of fine reticular fibers around the central vein and around the elements of the portal tract. The reticular fibers in between the hepatic cords appeared fine and interrupted Fig. (25T). Semi-thin sections revealed that 
all hepatocytes appeared with massive cytoplasmic vacuoles. Most of the hepatocytes became irregular in shape, few hepatocytes became enlarged but still polyhedral. The nuclei of the hepatocytes appeared either rounded vesicular with normal size or enlarged with two nucleoli. Some hepatocytes had irregular small deeply stained nuclei. Von Kupffer cells and endothelial cells were seen lining the dilated blood sinusoids which contained red blood corpuscles Fig. (26T).

The electron microscopic examination of liver sections of citalopram treated albino rat mothers (subgroup IIB) revealed that the hepatocyte appeared enlarged. The nuclei of the hepatocytes became small with an irregular nuclear envelope and an apparent increase of their heterochromatin content Figs. (27T,28T). Some mitochondria swell and lost of their cristae and matrix Fig. (28T). Most of the rough endoplasmic reticulum became irregularly arranged and dispersed with apparent increase in their surface ribosomes. Some elongated and distended rough endoplasmic reticulum became encircled to the mitochondria Fig. (28T). Some dilated smooth endoplasmic reticulum appeared within the cytoplasm Fig. (28T). Some phagosomes and autophagous vacuoles enclosing myelin figures appeared within the cytoplasm Fig. (28T). The glycogen granules appeared to be more or less than those of the control one Figs. (21 T,28T). Numerous partially leached lipid droplets were seen within the cytoplasm of some hepatocytes Fig. (28T). The microvilli in the space of Diss could not be recognized Fig. (27T). The bile canaliculus couldn't be recognized Fig. (27T). The blood sinusoids were lined by von Kupffer cells and contained red blood corpuscles. Some von Kupffer cells had irregular heterochromatic nuclei and contained cytoplasmic vacuoles, phagosomes and primary lysosome in their cytoplasm. Few collagen fibrils were seen in the wall of the blood sinusoid Fig. (27T).
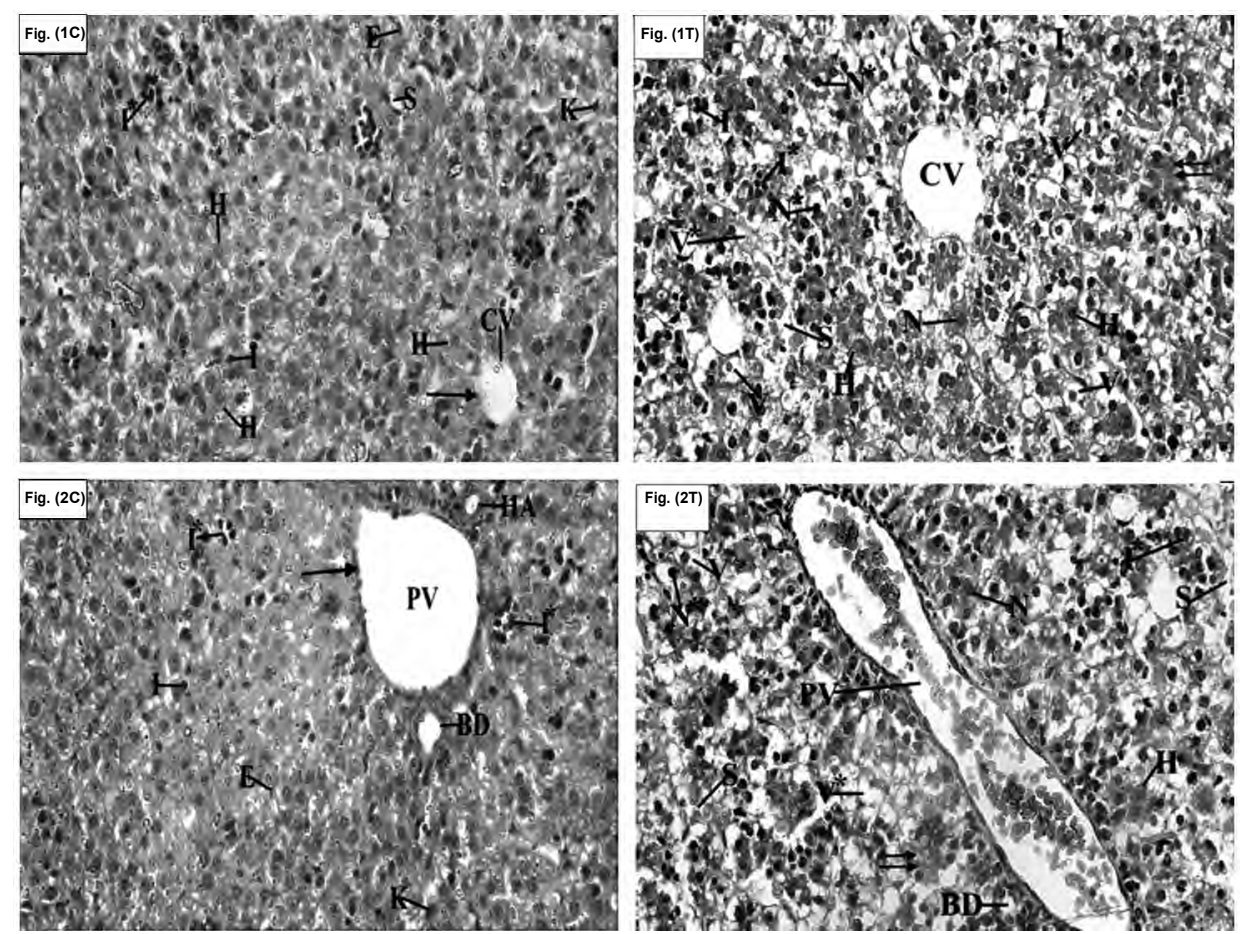

Fig. (1 C): A photomicrograph of a transverse section of the liver of one day old albino rat offspring of control mother (subgroup IA) to show that the Hepatocytes $(\mathrm{H})$ are irregularly arranged around the Central Vein $(\mathrm{CV})$ which is lined by flat endothelial cells (arrow). Notice the presence of irregular shaped blood sinusoids (S) which are lined by Endothelial cells (E) and von Kupffer cells (K). Also, notice the presence of the hemopoietic cells (I) and the hemopoietic islets (I*). (HX. \& E. X400).

Fig. (2C): A photomicrograph of a transverse section of the liver of one day old albino rat offspring of control mother (subgroup IA) to show that the portal tract contains a branch of the Portal Vein (PV) which is lined with flat endothelial cells (arrow), a branch of Hepatic Artery (HA) and an interlobular Bile Ductule (BD). Notice the presence of the hemopoietic cells (I), the hemopoietic islets (I*), the blood Sinusoids (S), the Endothelial cell (E) and von Kupffer cell (K). (HX. \& E. X400).

Fig. (1 T): A photomicrograph of a transverse section of the liver of one day old albino rat offspring of citalopram treated mother (subgroup IIA) to show that the Central Vein (CV) is dilated and most of the hepatocytes have Vacuolated cytoplasm (V). Notice the presence of the hemopoietic cells (I), the hemopoietic Islets $\left(I^{*}\right)$, area of completely Vacuolated cells ( $\left.\mathrm{V}^{*}\right)$, homogenous areas of cytoplasm ( ) and dilated blood sinusoids (S). Also, notice the presence of few Hepatocytes $(\mathrm{H})$ with vesicular nuclei (N) and notice small deeply stained Nuclei (N*). (HX. \& E. X400).

Fig. (2T): A photomicrograph of a transverse section of the liver of one day old albino rat offspring of citalopram treated mother (subgroup IIA) to show markedly dilated Portal Vein (PV) which is engorged with blood. Some hepatocytes have vacuolated cytoplasm (V). Notice the presence of many hemopoietic islets $\left(\mathrm{I}^{*}\right)$, Vacuolated areas $\left(\mathrm{V}^{*}\right)$, homogenous areas of cytoplasm ( ) and dilated blood sinusoids (S). Also, notice the presence of an interlobular bile ductule (BD), few polyhedral hepatocytes (H), vesicular nuclei $(\mathrm{N})$ and small deeply stained nuclei $\left(\mathrm{N}^{*}\right)$. (HX. \& E. X400). 

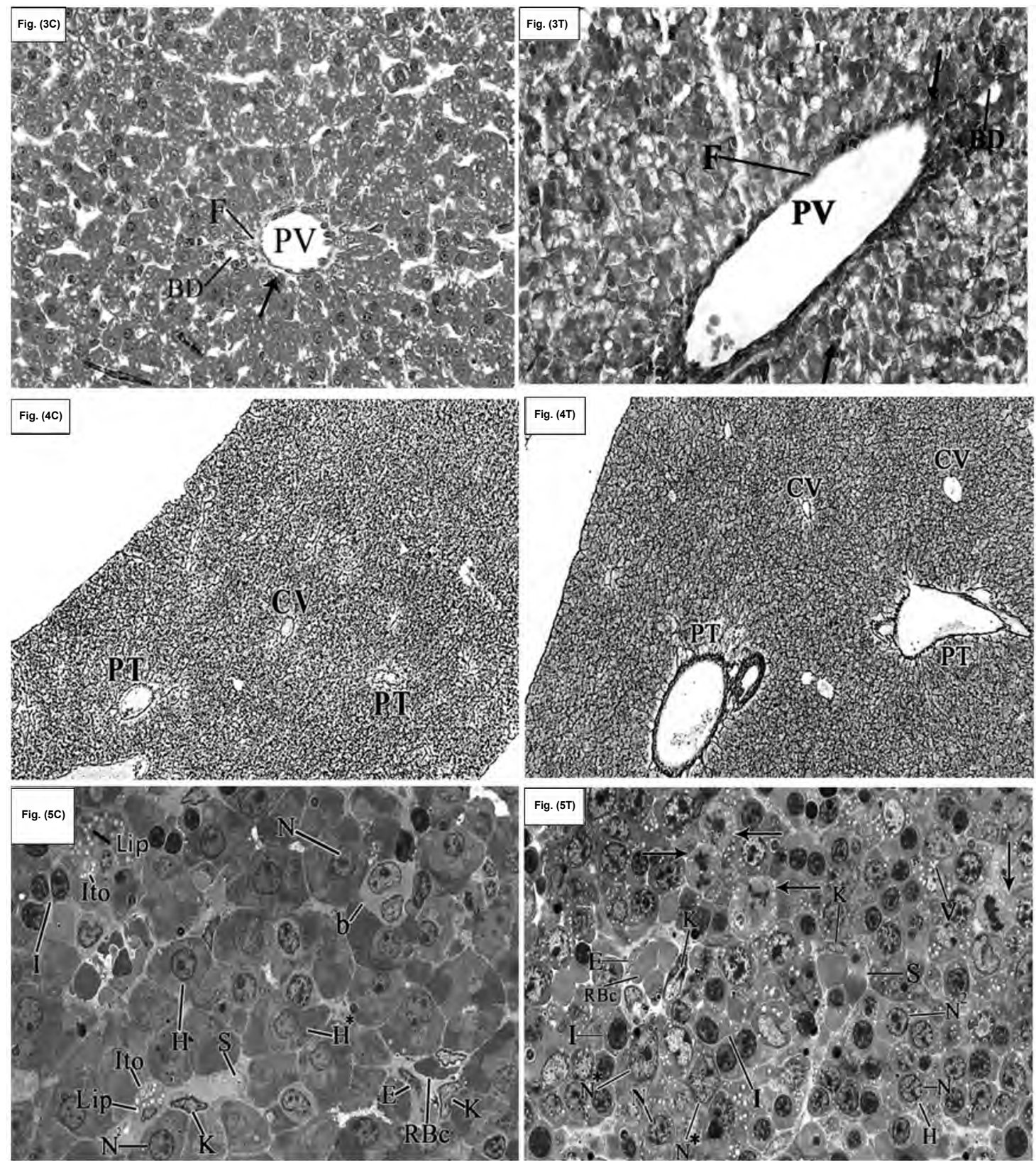

Fig. (3C): A photomicrograph of a transverse section of the liver of one day old albino rat offspring of control mother (subgroup IA) to show the distribution of faint collagen fibers (F) around the portal vein (PV) and interlobular bile ductule (BD) and for a short distance along the wall of the blood sinusoids which are adjacent to the portal tract (arrow). (Masson's trichrome X400).

Fig. (4C): A photomicrograph of a transverse section of the liver of one day old albino rat offspring of control mother (subgroup IA) to show distribution of delicate reticular fibers around the central vein (CV), in between the hepatocytes and around the portal tract (PT). (Gordon \& Sweets Silver Stain X100).

Fig. (5C): A photomicrograph of semi-thin section of the liver of one day old albino rat offspring of control mother (subgroup IA) to show that some hepatocytes $(\mathrm{H})$ appear nearly polyhedral in shape with vesicular nucleus $(\mathrm{N})$ while others appear irregular in shape $\left(\mathrm{H}^{*}\right)$. Notice the presence of blood sinusoid $(\mathrm{S})$ which is lined by von Kupffer cells $(\mathrm{K})$ and endothelial cell (E) and contains red blood corpuscles (RBcs). Also, notice the presence haemopoietic cells (I) forming hemopoietic islet, binucleated hepatocytes (b), few nuclei with 2 nucleoli (N2) and Ito cells (Ito) which contain lipid droplets (Lip). (Toluidine blue X1000).

Fig. (3T): A photomicrograph of a transverse section of the liver of one day old albino rat offspring of citalopram treated mother (subgroup IIA) to show an increase of the collagen fibers $(\mathrm{F})$ around a branch of portal vein $(\mathrm{PV})$ and around the interlobular bile ductules (BD). Notice presence of collagen fibers for a short distance along the wall of the blood sinusoids which are adjacent to the elements of the portal tract (arrows). (Masson's trichrome X400).

Fig. (4T): A photomicrograph of a transverse section of the liver of one day old albino rat offspring of citalopram treated mother (subgroup IIA) to show the distribution of delicate reticular fibers around the central vein (CV), in between the hepatocytes and an apparent increase in their condensation around the portal tract (PT). (Gordon \& Sweets Silver Stain X100).

Fig. (5T): A photomicrograph of a semi-thin section of the liver of one day old albino rat offspring of citalopram treated mother (subgroup IIA) to show that some hepatocytes $(\mathrm{H})$ appear nearly polyhedral in shape with vesicular rounded nucleus containing one nucleolus $(\mathrm{N})$ or two nucleoli $(\mathrm{N} 2)$ while others appear irregular in shape with large nuclei $\left(\mathrm{N}^{*}\right)$. The hepatocytes show cytoplasmic vacuolation (V). Some hepatocytes show mitotic figures (arrows). Von Kupffer cells (K) and the endothelial cells (E) line the blood sinusoids (S) which are dilated and engorged with red blood corpuscles (RBc). Notice the presence haemopoietic cells (I) that forming the haemopoietic islets. (Toluidine blue X1000). 

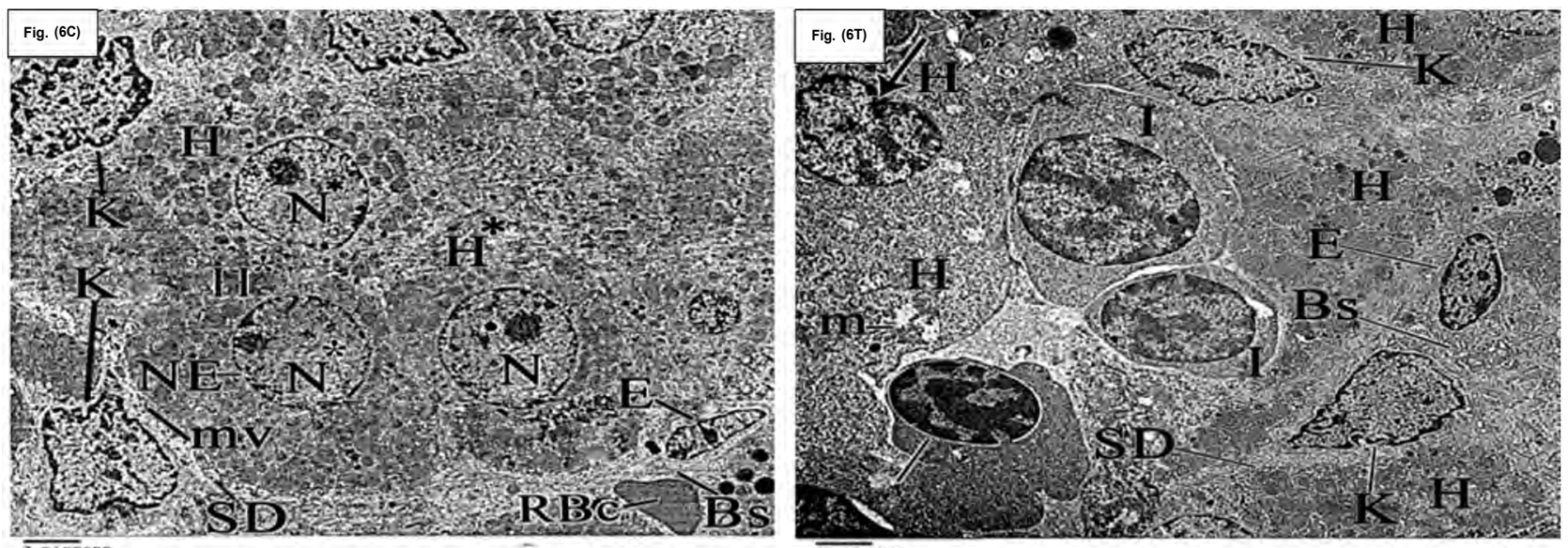

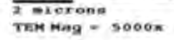
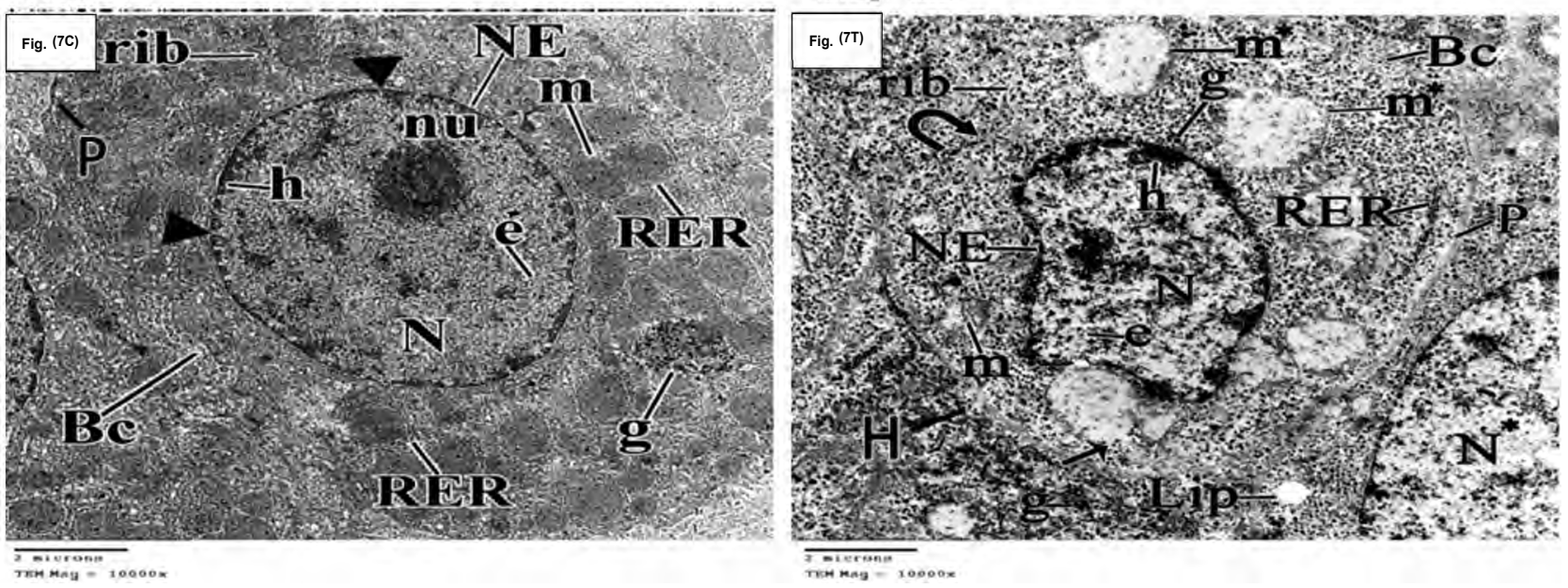

Fig. (6C): An electron micrograph of ultrathin section of the liver of one day old albino rat offspring of control mother (subgroup IA) to show the presence of the dark hepatocytes $\left(\mathrm{H}^{*}\right)$ and light hepatocytes $(\mathrm{H})$. The hepatocytes contain large, spherical and nearly centrally nucleus $(\mathrm{N})$ or eccentric nucleus $\left(\mathrm{N}^{*}\right)$. The nucleus is surrounded by well-developed nuclear envelope (NE). Notice the presence of von Kupffer cells (K), the endothelial cell (E) line the wall of the blood sinusoids and the red blood corpuscles (RBc) within the lumen of the blood sinusoid (Bs). Also, notice the presence of undeveloped microvilli (mv) which project from the basal surface of hepatocytes into the space of Diss (SD). (TEM Mag. X5000).

Fig. (7C): An electron micrograph of ultrathin section of the liver of one day old albino rat offspring of control mother (subgroup IA) to show the hepatocyte with an intact plasma membrane $(\mathrm{P})$ and contains large, spherical nucleus $(\mathrm{N})$ with a prominent nucleolus (nu). Notice that the nucleus is surrounded by well-developed nuclear envelope (NE) which contains nuclear pores (arrow heads). Notice the presence of euchromatin (e) and heterochromatin (h), mitochondria (m), rough endoplasmic reticulum (RER), free ribosomes (rib) and glycogen granules (g) which are present in cluster. Also, notice the presence of microvilli which are projecting from the hepatocytes into the bile canaliculus (Bc). (TEM Mag. X10000).

Fig. (6T): An electron micrograph of ultrathin section of the liver of one day old albino rat offspring of citalopram treated mother (subgroup IIA) to show that the blood sinusoid (Bs) is lined by von Kupffer cells (K) and endothelial cell (E). Notice the presence of haemopoietic cells (I) with rounded heterochromatic nuclei. Also, notice the presence of the hepatocytes with an indentated nucleus (arrow), the mitochondria (m) which e partially lose their matrix and cristae and notice also the glycogen granules (g). (TEM Mag. X5000).

Fig. (7T): An electron micrograph of ultrathin section of the liver of one day old albino rat offspring of citalopram treated mother (subgroup IIA) to show part of the hepatocyte with ill defined plasma membrane (P) in small area (curved arrow) and an indentated nucleus (N) which is surrounded by nuclear envelope (NE). Notice that most of the mitochondria are swollen and show complete loss of their matrix and cristae $\left(\mathrm{m}^{*}\right)$ while few partially loss their matrix and still have cristae $(\mathrm{m})$ and other mitochondria appear raptured (arrow). Notice the presence of. glycogen granules (g), free ribosomes (rib), leached lipid droplet (Lip), rough endoplasmic reticulum (RER), part of large nucleus ( $\mathrm{N}^{*}$ ) and bile canaliculus (Bc). (TEM Mag. X10000). 

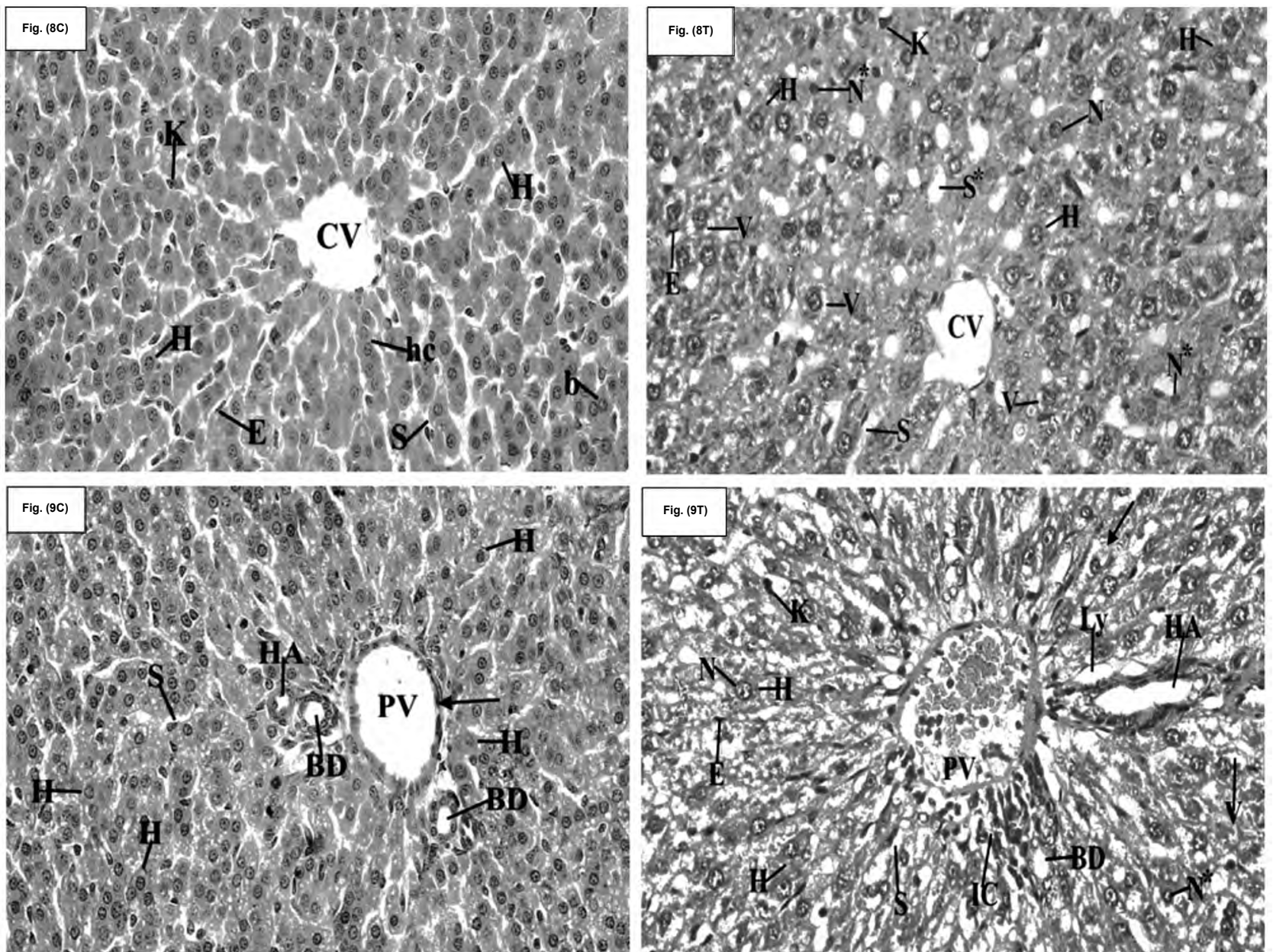

Fig. (8C): A photomicrograph of a transverse section of the liver of 15 days old albino rat offspring of control mother (subgroup IB) to show that the hepatocytes $(\mathrm{H})$ are polyhedral in shape with vesicular nuclei and arrange in cords (hc) which radiate from the central vein (CV) and they are separated by the blood sinusoids (S). Notice that the blood sinusoids are lined with flat endothelial cells (E) and von Kupffer cells (K). Also, notice the presence of some binucleated hepatocyte (b). (HX. \& E. X400).

Fig. (9C): A photomicrograph of a transverse section of the liver of 15 days old albino rat offspring of control mother (subgroup IB) to show that the portal tract contains a branch of the portal vein (PV) which is lined with flat endothelial cells (arrow), thick walled branch of hepatic artery (HA) and an interlobular bile ductules (BD) which is lined with cuboidal epithelium cells. Notice that the hepatocytes (H) are polyhedral in shape with rounded vesicular nuclei and separated by the blood sinusoids (s). (HX. \& E. X400).

Fig. (8T): A photomicrograph of a transverse section of the liver of 15 days old albino rat offspring of citalopram treated mother (subgroup IIB) to show that the hepatocytes $(\mathrm{H})$ irregularly arrange around the central vein $(\mathrm{CV})$. Notice the presence of polyhedral hepatocytes $(\mathrm{H})$ with rounded vesicular nuclei $(\mathrm{N})$, other hepatocytes with small vacuoles $(\mathrm{V})$ and few hepatocytes have small and deeply stained nuclei $\left(\mathrm{N}^{*}\right)$. Also, notice that most of the blood sinusoids lose their radial arrangement and become irregular in shape ( $\left.\mathrm{S}^{*}\right)$ while others have slit like appearance (S) and they are lined with the endothelial cells (E) and von Kupffer cells (K). (HX. \& E. X400).

Fig. (9T): A photomicrograph of a transverse section of the liver of 15 days old albino rat offspring of citalopram treated mother (subgroup IIB) to show that the portal tract contains dilated branch of portal vein (PV) which is engorged with blood, thick wall dilated branch of the hepatic artery (HA), an interlobular bile ductule (BD) and the lymph vessels (Ly). Notice that most of the hepatocytes have small vacuoles (V), some hepatocytes have ill defined cell bounderies with cytoplasmic vacuolation (arrow). Some nuclei of the hepatocytes are rounded and $\operatorname{vesicular}(\mathrm{N})$ and others are small and deeply stained nuclei $\left(\mathrm{N}^{*}\right)$. Also, notice, von Kupffer cells $(\mathrm{K})$ and the endothelial cells $(\mathrm{E})$ line the blood sinusoids (S), few inflammatory cells surround the portal tract (IC). (HX. \& E. X400). 

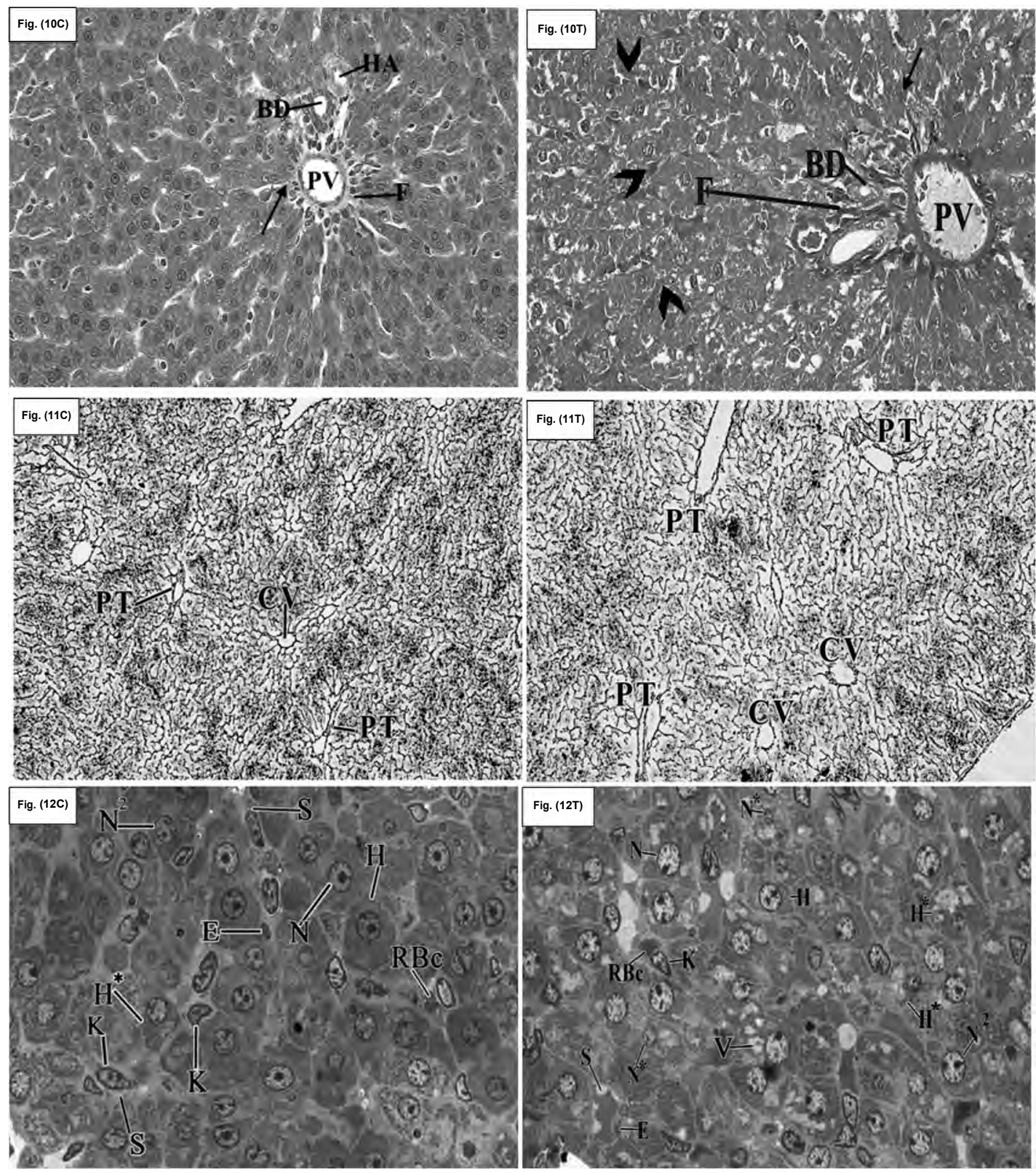

Fig. (1 OC): A photomicrograph of a transverse section of the liver of 15 days old albino rat offspring of control mother (subgroup IB) to show a faint collagen fibers $(\mathrm{F})$ around the elements of the portal tract which are a branch of the portal vein (PV), a branch of the hepatic artery (HA) and an interlobular bile ductules (BD) and for a short distance along the wall of the blood sinusoids which are adjacent to the portal tract (arrow). (Masson's trichrome X400).

Fig. (1 1C): A photomicrograph of a transverse section of the liver of 15 days old albino rat offspring of control mother (subgroup IB) to show the distribution of fine reticular fibers around the central vein (CV), in between the hepatocytes and around the portal tract (PT). Notice that the hexagonal hepatic lobule is defined well. (Gordon \& Sweets Silver Stain X100).

Fig. (12C): A photomicrograph of semi-thin section of the liver of 15 days old albino rat offspring of control mother (subgroup IB) to show that most of the hepatocytes $(\mathrm{H})$ appear polyhedral in shape with large, rounded, vesicular and central nuclei containing one nucleoli $(\mathrm{N})$ or two nucleoli (N2). Notice that few of the hepatocytes are irregular in shape with eccentric nuclei $\left(\mathrm{H}^{*}\right)$. Notice the presence of von Kupffer cells $(\mathrm{K})$ and the endothelial cells $(\mathrm{E})$ that line the wall of the blood sinusoids and notice the red blood corpuscles (RBc) within the lumen of the blood sinusoids (S). (Toluidine blue X1000).

Fig. (10T): A photomicrograph of a transverse section of the liver of 15 days old albino rat offspring of citalopram treated mother (subgroup IIB) to show mild distribution of the collagen fibers (F) around the elements of the portal tract which are a branch of the portal vein (PV), a branch of hepatic artery (HA) and a tributary of an interlobular bile ductules (BD and long the wall of the blood sinusoids which are adjacent to the elements of the portal tract (arrow). Notice presence of collagen fibers in the wall of the blood sinusoids (arrow heads). (Masson's trichrome X400).

Fig. (11 T): A photomicrograph of a transverse section of the liver of 15 days old albino rat offspring of citalopram treated mother (subgroup IIB) to show the distribution of fine reticular fibers around the central vein (CV), in between the hepatocytes and around the portal tract (PT). (Gordon \& Sweets Silver Stain X100).

Fig.(12T): A photomicrograph of a semi-thin section of the liver of 15th day old albino rat offspring of citalopram treated mother of subgroup IIB to show that some hepatocytes appear irregular in shape $\left(\mathrm{H}^{*}\right)$ with vacuolated cytoplasm and small dark nuclei $\left(\mathrm{N}^{*}\right)$ while other hepatocytes $(\mathrm{H})$ appear polyhedral in shape with rounded vesicular nuclei $(\mathrm{N})$ and vacuolated cytoplasm $(\mathrm{V})$. Notice the presence of blood sinusoids (S), von Kupffer cells (K), endothelial cells (E), red blood corpuscles (RBc) and presence of two nucleoli within some nuclei (N2) of the hepatocytes. (Toluidine blue X1000). 

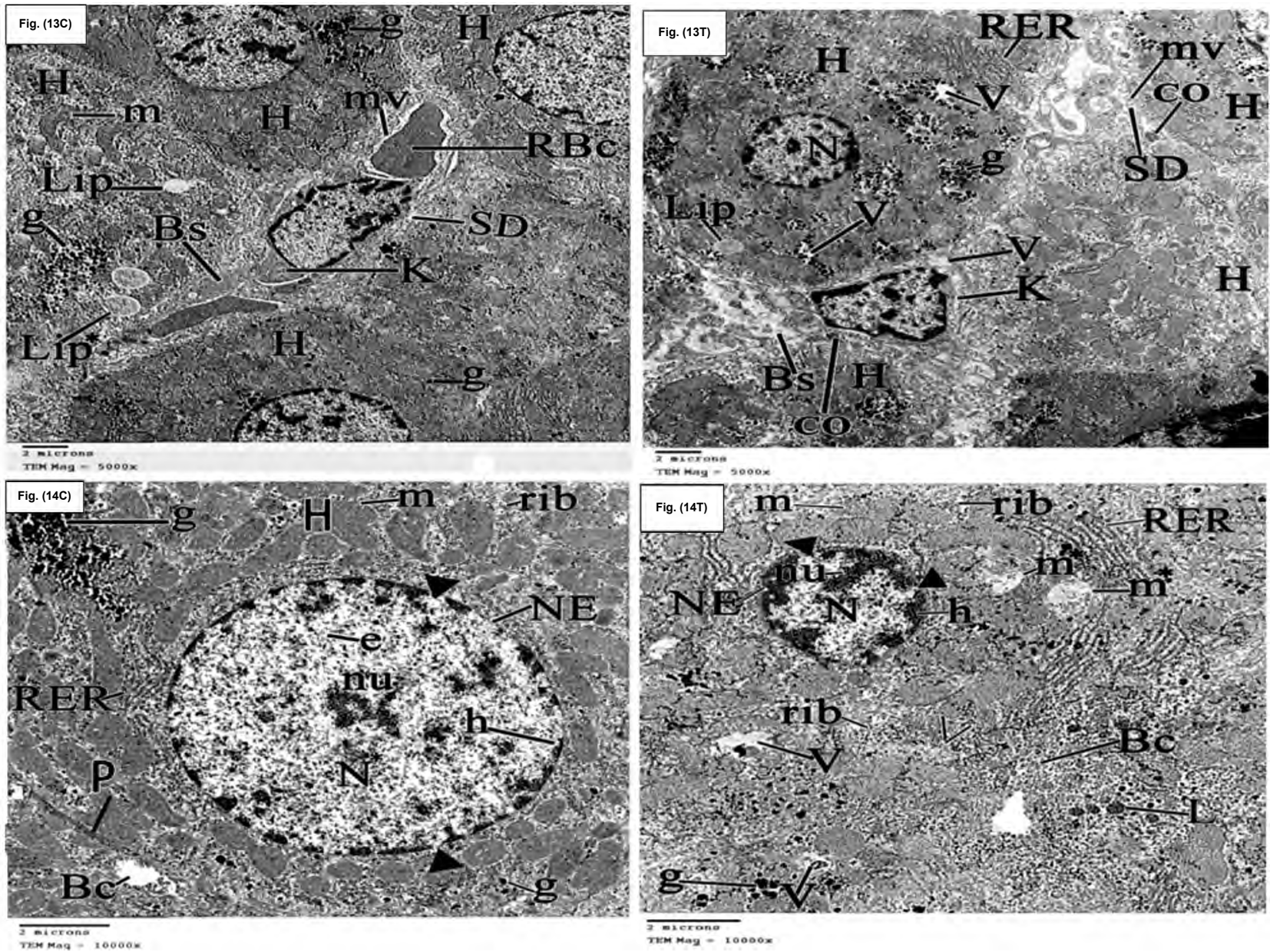

Fig. (1 3C): An electron micrograph of ultrathin section of the liver of 15 days old albino rat offspring of control mother (subgroup IB) to show the blood sinusoid (Bs) between the hepatocytes $(\mathrm{H})$ which is lined by von Kupffer cells $(\mathrm{K})$ and contains red blood corpuscle (RBc). Notice the presence of microvilli (mv) of the hepatocytes project into the space of Diss (SD), leached lipid (Lip) and partially leached lipid (Lip*) droplets, mitochondria (m) and glycogen granules (g). (TEM Mag. X5000).

Fig. (1 4C): An electron micrograph of ultrathin section of the liver of 15 days old albino rat offspring of control mother (subgroup IB) to show part of the hepatocyte $(\mathrm{H})$ that contains spherical eccentric nucleus $\left(\mathrm{N}^{*}\right)$ which is surrounded by a well-developed nuclear envelope (NE) and has many nuclear pores (arrow heads). Notice that the nucleus contains euchromatin (e), heterochromatin (h) and central nucleolus (nu). Notice the presence of the mitochondria (m), the rough endoplasmic reticulum (RER), the glycogen granules (g), free ribosomes (rib) and the bile canaliculus (Bc) which contains microvilli. (TEM Mag. X10000).

Fig. (13T): An electron micrograph of ultrathin section of the liver of 15 days old albino rat offspring of citalopram treated mother (subgroup IIB) to show blood sinusoid (Bs) which contains few collagen fibrils (CO) in its wall. Notice the appearance of microvilli (mv), space of Diss (SD) and von Kupffer cells $(\mathrm{K})$ which contain vacuoles $(\mathrm{V})$. Also, notice the presence of the hepatocyte $(\mathrm{H})$ contains small irregular nucleus $(\mathrm{N})$, cytoplasmic vacuoles (V), partially leached lipid droplet (Lip), dispersed rough endoplasmic reticulum (RER) and glycogen granules (g) (TEM Mag. X5000).

Fig. (14T): An electron micrograph of ultrathin section of the liver of 15 days old albino rat offspring of citalopram treated mother (subgroup IIB) to show that the nucleus $(\mathrm{N})$ of the hepatocyte is surrounded by well-developed nuclear envelope (NE) which has nuclear pores (head arrow). Notice the increase of the heterochromatin $(\mathrm{h})$, mitochondria $(\mathrm{m})$, some mitochondria partially lose their matrix ( $\left.\mathrm{m}^{*}\right)$, vacuole $(\mathrm{v})$ dilated rough endoplasmic reticulum (RER), glycogen granules $(\mathrm{g})$ and primary lysosomes $(\mathrm{L})$. Notice the presence of dilated bile canaliculus (Bc) between adjacent hepatocytes. (TEM Mag. X10000). 

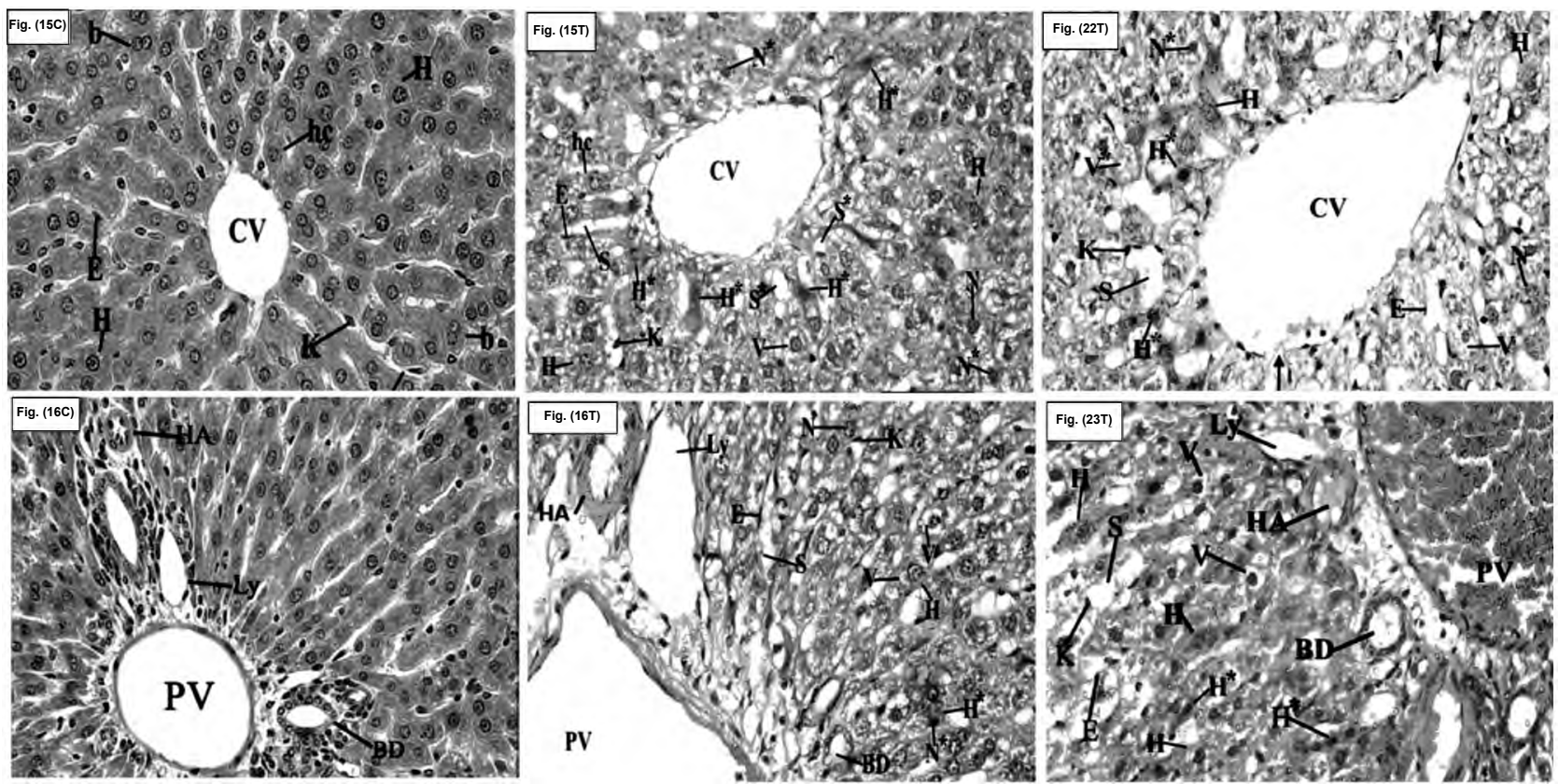

Fig. (15C): A photomicrograph of a transverse section of the liver of the control albino rat mother (group I) to show that the hepatocytes (H) are polyhedral with large, vesicular, rounded and central nuclei and arrange in cords (hc) radiating from the central vein $(\mathrm{CV})$. The hepatocytes are separated by the blood sinusoids (s) which are lined with flat endothelial cells (E) and von Kupffer cells (K). Notice the presence of binucleated hepatocytes (b). (HX. \& E. X400).

Fig. (16C): A photomicrograph of a transverse section of the liver of the control albino rat mother (group I) to show that the portal tract contains a branch of the portal vein (PV), a branch of the hepatic artery (HA), an interlobular bile ductule (BD) and lymph vessel (Ly). (HX. \& E. X400).

Fig. (15T): A photomicrograph of a transverse section of the liver of citalopram treated albino rat mother on the 1st day after delivery (subgroup IIA) to show that most of the hepatic cords (hc) and the blood sinusoids ( $\mathrm{S}^{*}$ ) lose their radial arrangement around the dilated central vein $(\mathrm{CV})$. Few hepatocytes $(\mathrm{H})$ are polyhedral with rounded vesicular nuclei while most of them have ill defined cell boundaries with vesicular nuclei $(\mathrm{N})$ or with small deeply stained nuclei $\left(\mathrm{N}^{*}\right)$ and vacuolated cytoplasm $(\mathrm{V})$. Few hepatocytes have an eosinophilic homogenous cytoplasm and deeply stained nuclei $\left(\mathrm{H}^{*}\right)$. Notice, the endothelial cells (E) and von Kupffer cells (K). (HX. \& E. X400).

Fig. (16T): A photomicrograph of a transverse section of the liver of citalopram treated albino rat mother on the 1st day after delivery (subgroup IIA) to show part of the portal tract contains markedly dilated branch of the portal vein (PV), dilated branch of hepatic artery (HA), dilated lymph vessels (Ly) and an interlobular bile ductule (BD). Notice that some of hepatocytes have vacuolated cytoplasm (V) with vesicular nuclei while others have deeply stained nuclei $\left(\mathrm{N}^{*}\right)$ and some hepatocytes are polyhedral $(\mathrm{H})$ with rounded and vesicular nuclei $(\mathrm{N})$. Also, notice the presence of dilated blood sinusoids (S), von Kupffer cells (K) and endothelial cells (E). (HX. \& E. X400).

Fig. (22T): A photomicrograph of a transverse section of the liver of citalopram treated albino rat mother on the 15th day after delivery (subgroup IIB) to show markedly dilated central vein (CV) with disturbance of its endothelial lining (arrows). The hepatocytes have vacuolated cytoplasm (v) and deeply stained irregular nuclei $\left(\mathrm{N}^{*}\right)$ or vesicular nuclei $(\mathrm{N})$ while few hepatocytes appear polyhedral $(\mathrm{H})$ with vesicular nuclei. Notice that some hepatocytes show an increased eosinophilia with small deeply stained nuclei $\left(\mathrm{H}^{*}\right)$. Also, notice the presence of von Kupffer cells (K) and endothelial cells (E) that line the dilated blood sinusoids (S) and the hepatocytes with vacuoles ( $\mathrm{v}^{*}$ ) containing remnant of cytoplasm. (HX. \& E. X400)

Fig. (23T): A photomicrograph of a transverse section of the liver of citalopram treated albino rat mother on the 15th day after delivery (subgroup IIB) to show the dilated and congested branch of the portal vein (PV), the dilated thick wall branch of the hepatic artery (HA), the dilated interlobular bile ductule (BD) and the dilated lymph vessels (Ly). Notice that some hepatocytes show an increased eosinophilia with small deeply stained nuclei $\left(\mathrm{H}^{*}\right)$, others have vacuolated cytoplasm $(\mathrm{v})$ while most of the hepatocytes appear polyhedral $(\mathrm{H})$ with vesicular nuclei. (HX. \& E. X400). 

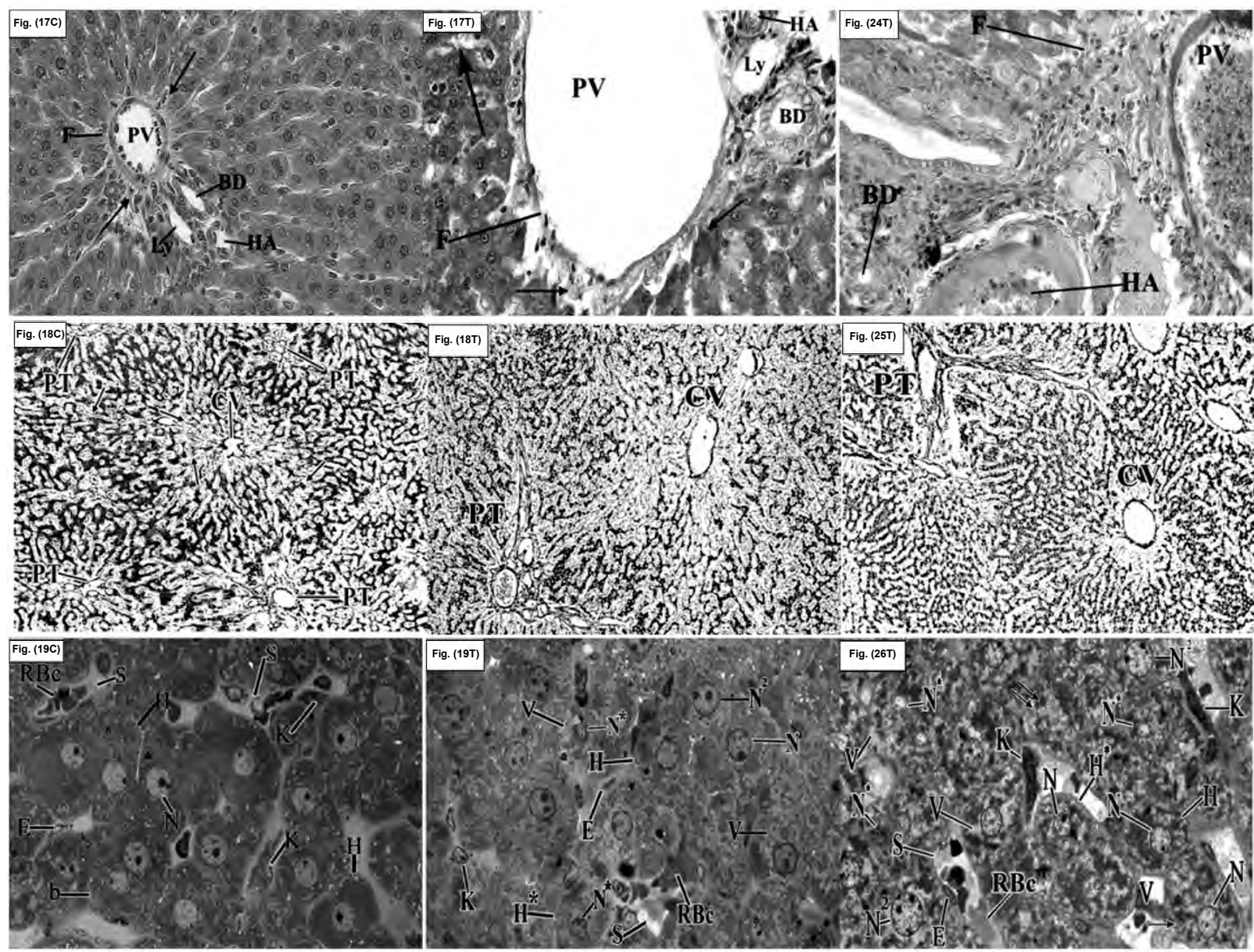

Fig. (17C): A photomicrograph of a transverse section of the liver of the control albino rat mothers (group I) to show the normal distribution of collagen fibers (F) around the elements of the portal tract which are a branch of the portal vein (PV), a branch of the hepatic artery (HA), a tributary of an interlobular bile ductule (BD) and lymph vessel (Ly) and for a short distance along the wall of the blood sinusoids which are adjacent to the elements of the portal tract (arrows). (Masson's trichrome X400).

Fig. (18C): A photomicrograph of a transverse section of the liver of the control albino rat mother (group I) to show that the framework of indistinct hexagonal hepatic lobule is formed from reticular fibers. Notice the presence of reticular fibers around central vein (CV), in between hepatocytes and around the elements of the portal tract (PT). (Gordon \& Sweets Silver Stain X100).

Fig. (19C): A photomicrograph of semi-thin section of the liver of the control albino rat mother (group I) to show that all hepatocytes (H) are polyhedral in shape with large, central, rounded and vesicular nuclei (N). Von Kupffer cells (K) and endothelial cell (E) line the blood sinusoids. Red blood corpuscles (RBcs) are within the lumen of the sinusoids (S). Notice the presence of binucleated hepatocyte (b). (Toluidine blue X1000).

Fig. (17T): A photomicrograph of a transverse section of the liver of citalopram treated albino rat mother on the 1st day after delivery (subgroup IIA) to show the distribution of collagen fibers (F) around the elements of the portal tract which are a branch of the portal vein (PV), a branch of the hepatic artery (HA), an interlobular bile ductule (BD) and lymph vessel (Ly). Notice that these fibers radiate for a short distance along the wall of the blood sinusoids which are adjacent to the elements of the portal tract (arrow). Also, notice presence of collagen fibrils in the wall of few blood sinusoids (arrow heads). (Masson's trichrome X400).

Fig. (18T): A photomicrograph of a transverse section of the liver of citalopram treated albino rat mother on the 1st day after delivery (subgroup IIA) to show disorganization of the hepatic lobule and condensation of the reticular fibers around the central vein (CV), in between the hepatic cords and around the portal tract (PT). (Gordon \& Sweets Silver Stain X100).

Fig. (19T): A photomicrograph of semi-thin section of the liver of citalopram treated albino rat mother on the 1st day after delivery (subgroup IIA) to show that most of hepatocytes $(\mathrm{H})$ are polyhedral in shape with rounded vesicular nuclei with one (N) or two nucleoli $(\mathrm{N} 2)$ while other hepatocytes appear irregular in shape $\left(\mathrm{H}^{*}\right)$ with small deeply stained nuclei ( $\left.\mathrm{N}^{*}\right)$. Notice the presence of cytoplasmic vacuolation $(\mathrm{V})$ in the hepatocytes, the blood sinusoids (S), von Kupffer cells (K), the endothelial cells (E) and red blood corpuscles (RBc). (Toluidine blue $\mathrm{X} 1000)$.

Fig. (24T): A photomicrograph of a transverse section of the liver of citalopram treated albino rat mother on the 15 th day after delivery (subgroup IIB) to show a marked increase in the collagen fibers (F) around the elements of the portal tract which are a branch of the portal vein (PV), a branch of the hepatic artery (HA) and an interlobular bile ductule (BD). Notice presence of collagen fibers for a short distance along the wall of some blood sinusoids which are adjacent to the elements of the portal tract (arrow). (Masson's trichrome X400).

Fig. (25T): A photomicrograph of a transverse section of the liver of citalopram treated albino rat mother on the 15th day after delivery (subgroup IVB) to show loss of the normal arrangement of the hexagonal hepatic lobules with an increased in the condensation of fine reticular fibers around the central vein $(\mathrm{CV})$ and around the elements of the portal tract (PT). The reticular fibers in between the hepatic cords appear fine and interrupted. (Gordon \& Sweets Silver Stain X100).

Fig. (26T): A photomicrograph of semi-thin section of liver of citalopram treated albino rat mother on the 15th day after delivery (subgroup IIB) to show that most of the hepatocytes are irregular in shape $\left(\mathrm{H}^{*}\right)$ and have cytoplasmic vacuolation (V) with rounded vesicular nuclei (N) or irregular small nuclei ( $\left.\mathrm{N}^{*}\right)$ while few hepatocytes appear enlarged (arrow) or polyhedral in shape $(\mathrm{H})$ and both have vesicular nuclei $(\mathrm{N})$, few nuclei have two nucleoli (N2), von Kupffer cells (K) and endothelial cells (E) line the dilated blood sinusoids(S) which contain red blood corpuscles $(\mathrm{RBc})$. Notice the presence of hepatocytes with ill defined nucleus and remnants of the cytoplasm (double arrow). (Toulidine blue; $\mathrm{X} 1000$ ). 

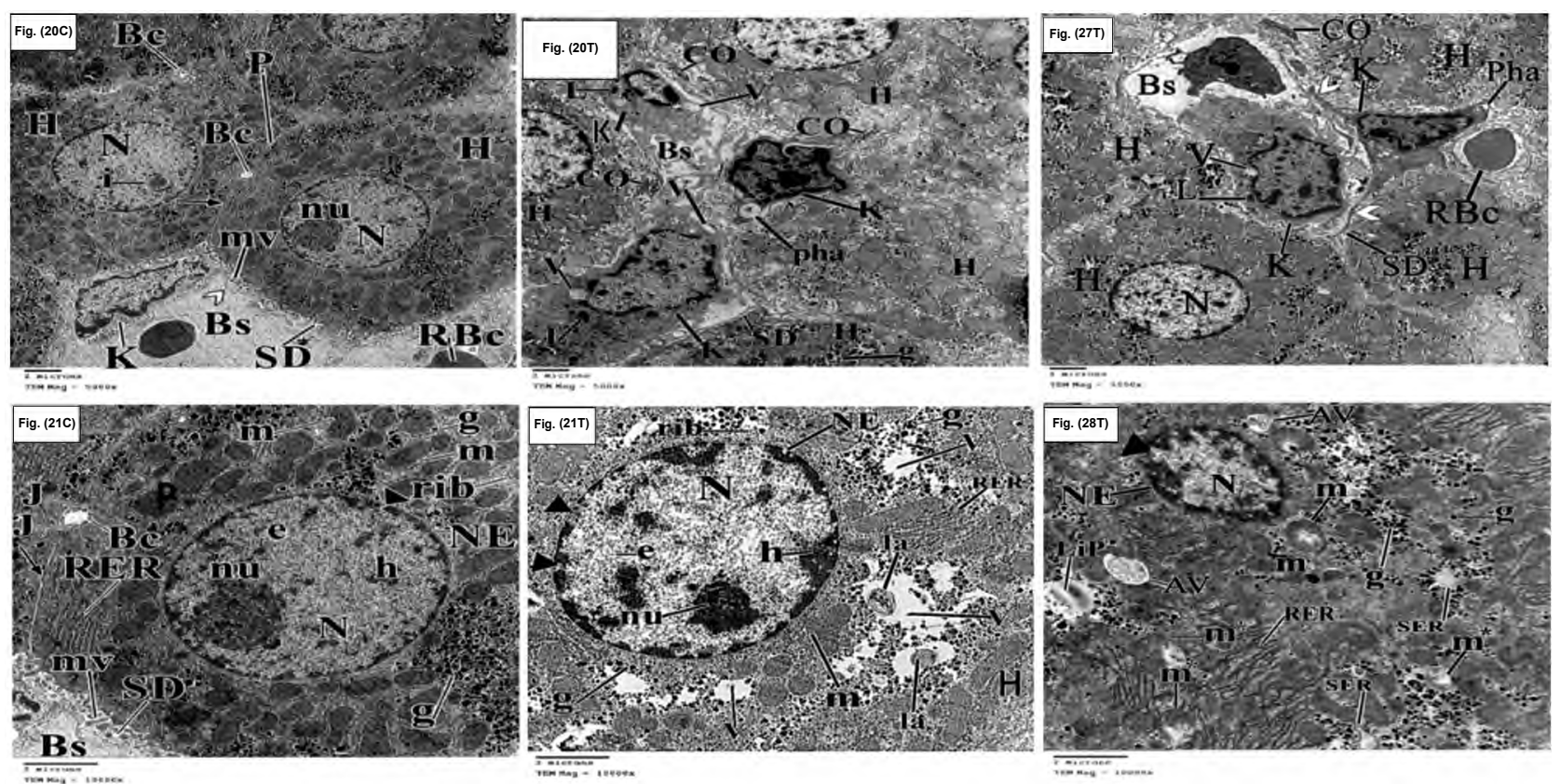

Fig. (20C): An electron micrograph of ultrathin section of the liver of the control albino rat mother (group I) to show that the hepatocytes $(\mathrm{H})$ appear polyhedral in shape with intact plasma membranes $(\mathrm{P})$ and contain large, spherical eccentric nuclei $(\mathrm{N})$. Notice that one of the nuclei contains eccentric nucleolus (nu) while the other one contains intranuclear pseudo inclusion body (i). Notice the presence of von Kupffer cell (K) with pseudopodia (white arrow head), red blood corpuscle (RBc), the blood sinusoid (Bs), space of Diss (SD), microvilli (mv) and bile canalicului (Bc) and desmosome (arrow). (TEM Mag. X5000).

Fig. (21C): An electron micrograph of ultrathin section of the liver of the control albino rat mother (group I) to show part of the hepatocyte with an intact plasma membrane (P) and large, spherical nucleus $(\mathrm{N})$ with a nuclear envelope (NE) which contains nuclear pores (arrow head). Notice that the nucleus contains an eccentric nucleolus (nu) and both euchromatin (e) and heterochromatin (h) within its karyoplasm. Notice the presence of the mitochondria $(\mathrm{m})$, the rough endoplasmic reticulum (RER), the free ribosomes (rib), the glycogen granules (g), the blood sinusoid (Bs), the bile canaliculus (Bc), junctional complexes (J) and desmosome (arrow). Also, notice the presence of well-developed microvilli (mv) in space of Diss (SD). (TEM Mag X10000).

Fig. (20T): An electron micrograph of ultrathin section of the liver of citalopram treated albino rat mother on the 1st day after delivery (subgroup IIA) to show the blood sinusoid (Bs) which contains collagen fibrils (CO) in its wall and is lined by numerous von Kupffer cells $(\mathrm{K})$ that contain primary lysosomes $(\mathrm{L})$, vacuoles $(\mathrm{V})$ and phagosomes (pha). Notice the presence of hepatocytes $(\mathrm{H})$, glycogen granules $(\mathrm{g})$ and space of Diss (SD). (TEM Mag. X5000).

Fig. (21 T): An electron micrograph of ultrathin section of the liver of citalopram treated albino rat mother on the 1st day after delivery (subgroup IIA) to show part of hepatocyte. Notice that the nucleus (N) is surrounded with an irregular nuclear envelope (NE) which contains nuclear pores (arrow heads) and it contains an eccentric nucleolus (nu) and both heterochromatin (h) and euchromatin (e). Notice the presence of multiple vacuoles in the cytoplasm (V) which are surrounded by glycogen granules (g) some of them contain lamellar body (la). Also, notice the presence of mitochondria $(\mathrm{m})$, rough endoplasmic reticulum (RER), free ribosomes (rib) and cytoplasmic degenerative area $\left(\mathrm{V}^{*}\right)$ enclosing lamellar body with electron dense granules. (TEM Mag. X10000).

Fig. (27T): An electron micrograph of ultrathin section of the liver of citalopram treated albino rat mother on the 15th day after delivery (subgroup IIB) to show the blood sinusoid (Bs) which is lined by von Kupffer cells (K) having pseudopodia (white arrow heads) and contains vacuoles $(\mathrm{V})$, primary lysosome $(\mathrm{L})$ and phagosomes (pha). Notice the presence of the hepatocytes $(\mathrm{H})$, collagen fibrils $(\mathrm{CO})$ and space of Diss (SD). (TEM Mag. X5000).

Fig. (28T): An electron micrograph of ultrathin section of the liver of citalopram treated albino rat mother on the 15 th day after delivery (subgroup IIB) to show part of the enlarged hepatocyte with small nucleus $(\mathrm{N})$ with an increased heterochromatin and an irregular nuclear envelope (NE) containing nuclear pore (arrow head). The cytoplasm contains some swollen mitochondria ( $\mathrm{m}^{*}$ ) with loss of their cristae and matrix. Notice the presence of elongated, distended and irregularly arranged rough endoplasmic reticulum (RER) around the mitochondria (m), some dilated smooth endoplasmic reticulum (SER), glycogen granules (g), partially leached lipid droplet (Lip) and presence of autophagous vacuoles enclosing myelin figures (AV). (TEM Mag. X10000). 
Table (1): Unpaired student's- $t$-test analysis of the albino rat mothers on the 1 st day after delivery (subgroups IA and IIA) regarding the level of serum enzymes of the livers.

\begin{tabular}{|c|c|c|c|c|}
\hline & $\begin{array}{c}\text { Control } \\
\text { (Subgroup } \\
\text { IA) }\end{array}$ & $\begin{array}{c}\text { Citalopram } \\
\text { treated } \\
\text { (Subgroup IIA) }\end{array}$ & $\begin{array}{r}\text { Inde } \\
\text { Sampl }\end{array}$ & $\begin{array}{l}\text { endent } \\
\text { student's } \\
\text { test }\end{array}$ \\
\hline & $\mathrm{No}=10$ & $\mathrm{NO}_{\mathrm{O}}=10$ & $t$ & $p$-value \\
\hline$A S T(I U / L):$ & & & & \\
\hline Mean \pm SD & $16.30 \pm 0.72$ & $128.57 \pm 5.91$ & 59.632 & $<0.001 * *$ \\
\hline$A L T(I U / L):$ & & & & \\
\hline Mean \pm SD & $13.18 \pm 2.03$ & $102.84 \pm 3.92$ & 47.113 & $<0.001 * *$ \\
\hline$G G T(U / L):$ & & & & \\
\hline Mean \pm SD & $14.14 \pm 0.53$ & $45.98 \pm 1.23$ & 75.177 & $<0.001 * *$ \\
\hline $\begin{array}{l}\text { Non-significa } \\
\text { Significant } \\
\text { Highly signif }\end{array}$ & $\begin{aligned} & :(p \text {-value } \\
: & (p \text {-value } \\
t & :(p \text {-value }\end{aligned}$ & $\begin{array}{l}0.05) \\
0.05) \\
0.001)\end{array}$ & & \\
\hline
\end{tabular}

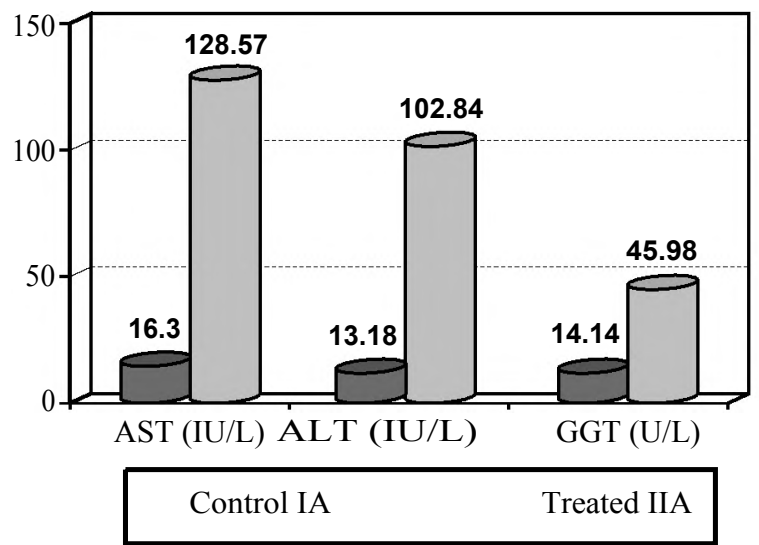

Graph (1): Bar chart representing mean levels of serum enzymes of the livers of the albino rat mothers on the 1 st day after delivery of control (Subgroups IA) and citalopram treated albino rat mothers (Subgroup IIA).

\section{Discussion}

In this study, the liver of the one day old control albino rat offspring was formed of irregular groups of hepatocytes around the central vein. They were separated by irregular shaped blood sinusoids and numerous hemopoietic cells and islets, these findings were in agreement with some authors $[19,20]$ The liver of fifteen day old albino rat offspring became more developed as compared to the liver of one day old. These findings were in agreement with other study [21]. The liver of albino rat mothers showed that the liver became fully developed, these findings were in line with some authors [22] The enzyme level of Aspartate Amino Transferase (AST), Alanine Aminotransferase (ALT) and Gamma Glutamyl Transpeptidase (GGT) in serum of the control albino rat mothers on the first and the fifteenth days after delivery were within normal range, these findings were the same as described by one study [23].
Table (2): Unpaired student's $t$-test analysis of the albino rat mothers on the 15 th day after delivery regarding the level of serum enzymes of the livers.

\begin{tabular}{|c|c|c|c|c|}
\hline & \multirow{2}{*}{$\begin{array}{c}\text { Control } \\
\text { (Subgroup } \\
\text { IB) } \\
\mathrm{No}=10\end{array}$} & \multirow{2}{*}{$\begin{array}{c}\text { Citalopram } \\
\text { treated } \\
\text { (Subgroup IIB) } \\
\text { No }=10\end{array}$} & \multicolumn{2}{|c|}{$\begin{array}{l}\text { Independent } \\
\text { Sample } \\
t \text {-test }\end{array}$} \\
\hline & & & $t$ & $p$-value \\
\hline \multicolumn{5}{|l|}{$A S T(I U / L):$} \\
\hline Mean \pm SD & $20.45 \pm 1.22$ & $195.29 \pm 5.96$ & 90.883 & $<0.001 * *$ \\
\hline \multicolumn{5}{|l|}{$A L T(I U / L):$} \\
\hline Mean \pm SD & $9.30 \pm 0.65$ & $108.11 \pm 1.54$ & 186.930 & $<0.001 * *$ \\
\hline \multicolumn{5}{|l|}{$G G T(U / L):$} \\
\hline Mean \pm SD & $14.71 \pm 0.39$ & $46.83 \pm 0.55$ & 150.647 & $<0.001^{* *}$ \\
\hline $\begin{array}{l}\text { Significant } \\
\text { Highly signific }\end{array}$ & $\begin{aligned}:(p \text {-value } \\
\text { ant }:(p \text {-value }\end{aligned}$ & $\begin{array}{l}0.05) \text {. } \\
0.05) \text {. } \\
0.001) .\end{array}$ & & \\
\hline
\end{tabular}

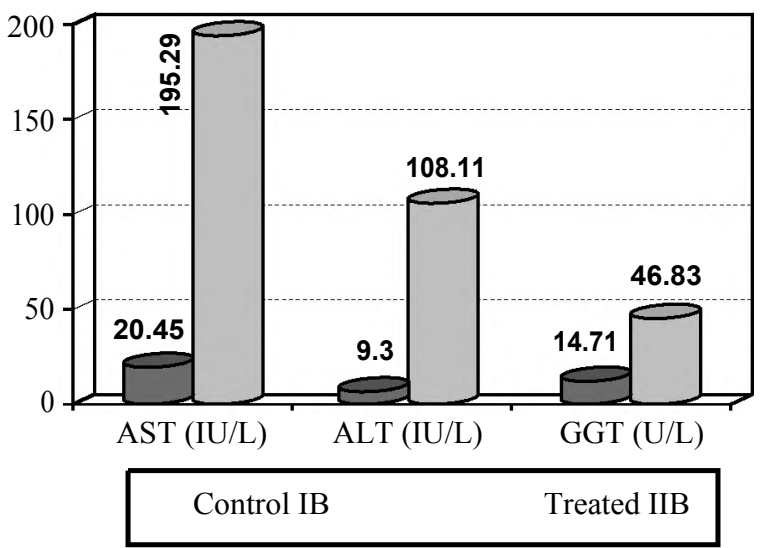

Graph (2): Bar chart representing mean level of serum enzymes of the livers of the albino rat mothers on the $15^{\text {th }}$ day after delivery of control and citalopram treated subgroups (Subgroups IB and IIB).

Citalopram used in this study as it was a psychotropic drug used to treat depression in pregnant or breast-feeding mothers as well as in the general population $[24,25]$

In the present study, the tissue damage in liver in response to citalopram administration was cleared by an elevation in the liver serum enzymes (AST, ALT and GGT) of citalopram treated mothers on the first and fifteenth days after delivery when compared with control groups. These findings were agreed with the study [26] that revealed that the serum transaminases were considered to be sensitive measure in evaluating hepatocellular damage. The alteration in such enzymes activities was mainly due to leakage of these enzymes from liver cytosol to the blood stream as a result of liver injury induced by citalopram. That study demonstrated that citalopram had tendency to produce hepatotoxicity in human. Citalopram markedly elevated serum concentration of the hepatic 
transaminases. The present study demonstrated that citalopram increased mean \pm SD of the 3 serum enzymes of the liver (AST, ALT and GGT). Comparison between the levels of the 3 serum enzymes of the livers using unpaired student's t test showed that there was a highly significant elevation ( $p$ value $<0.001$ ) in enzymes of the citalopram treated mothers on the 1 st and $15^{\text {th }}$ days after delivery. These statistical findings were in agreement with the study [27] that demonstrated the oxidative tissue damage induced by citalopram in different organs of the rats and found that there was a highly significant increase in the level of AST, ALT and GGT [26]. In a case study, citalopram increased the liver enzymes mainly alanine aminotransferase with a significant increased risk of liver injury [24]

In the present study, light microscopic results of the liver of citalopram treated albino rat mothers on the first and fifteenth days after delivery and their offspring showed degenerative changes in the liver parenchyma. These findings were in agreement with the study that demonstrated that administration of citalopram produced severe distortion of the hepatic architecture in the rat liver [26]. In this study, there was degeneration of the hepatocytes that appeared in the form of loss of their normal polyhydral shape, enlargement of some hepatocytes, loss of the cell boundaries, cytoplasmic vacuolation, hyperchromatic nuclei, and enlargement of some nuclei, necrosis and apoptosis of the hepatocytes. An increase in the mitotic figures was observed in the liver of one day old albino rats. The enlargement of hepatocytes and cytoplasmic vacuolation were explained by depletion of the ATP energy stores which was necessary to maintain the ionic and fluid homeostasis, resulting in reduced activity of the plasma membrane energy-dependent sodium pump (Na+, $\mathrm{K}+$-ATPase) [28] . Failure of this active transport system caused sodium to enter and accumulate inside cells and potassium to diffuse out followed by gain of water, causing cellular swelling [29]. The cytoplasmic vacoulaization attributed to accumulation of fat, proteins and water [30]. The apoptosis appeared in the form of shrinkage of cells with an increased eosinophilia and pyknosis (small deeply stained nuclei). Necrosis appeared as some hepatocytes lost their cell boundaries, their cytoplasm and their nuclei forming vacuoles areas containing remnants of cytoplasm. These findings were explained that apoptosis was considered as a feature in tissue toxicity of many chemical toxicants. DNA was the target of toxicants, and its damage was the leading cause for initiating the process of apoptosis. Consequently, apoptosis provided a means for eliminating critically damaged cells without disturbing tissue structure or function
[31]. In addition, dead cells showed an increased cytoplasmic eosinophilia due to an increased binding of eosin to the denatured intracytoplasmic protein. They also explained the nuclear changes in necrosis that was due to break down of DNA. They explained pyknosis by the nuclear shrinkage and an increased basophilia, the DNA condensed into a solid shrunken mass indicating cessation of DNA transcription [32] . Necrosis occurred as a result of depletion of Adenosine Triphosphate (ATP) due to oxidative stress, which led to disruption in the cellular homeostasis and the loss of the membrane integrity, triggering the release of cellular contents and culminating in an inflammatory response $[33,34]$

In present work, there was an increase in the mitotic figures which was explained in a study that the proliferation of hepatocytes was involved in liver regeneration that occurred after massive hepatocyte necrosis, or apoptosis induced by the hepatic toxins [35]. In the current study, the degenerative changes were more in the mothers fifteenth days after delivery and their offspring than in the mothers on the first day after delivery and their offspring. This suggestion was supported by a study on the liver of the guinea pigs, this study supposed that the changes which occurred with long duration of the therapy was due to more severe metabolic disruption in the hepatocytes. In the current work, the degenerative changes were more in the fifteen days old albino rats than in one day old. These results were suggested that citalopram crossed the placenta and passed into the breast milk, and therefore transferred to the infant, the amount of citalopram passed to breast milk and delivered to the infant correlated to the serum concentration of the mother [36,37]. In the present work, the degenerative changes in the hepatocytes were periportal more than pericentral in the offspring but appeared to be more pericentral than periportal in the mothers. The presence of degeneration in the periportal zones in the offspring was explained by the fact that cells in the periportal zone was the first to receive oxygen, nutrients, and toxins from the sinusoidal blood and were the first to show morphologic changes after bile duct occlusion (bile stasis) [38] . The presence of the degenerative changes in the pericentral zone more than in the periportal zone in the treated mothers was explained by studies which suggested that the pathological changes of the hepatocytes could be partially attributed to oxygen tension-gradient across the three hepatic zones, being higher in the periportal zone, therefore, the hepatocytes in the pericentral zone were exposed to lower concentra- 
tion of oxygen that made them more vulnerable to hepatocellular damage $[\mathbf{3 9 , 4 0 ]}$.

In this study, the hemopoietic cells and islets became more numerous within the parenchyma of the liver of one day old albino rat offspring of citalopram treated mothers. These results were in agreement with study which was done on fetal guinea pig exposed to hypoxia that produced stress erythropoiesis, a response that generated an increase in erythrocytes under condition of reduced oxygen supply [41]. In the present study, congestion and dilation of the portal veins, the central veins, the blood sinusoids, also dilation of the hepatic artery with inflammatory cellular infiltration in the portal area were seen in the liver of the mothers and their offspring. These findings were in agreement with some authors who reported that administration of citalopram induced oxidative stress associated with a significant increase in the activity of Xanthin Oxidase (XO) accompanied by elevated Nitric Oxide concentration (NO), this elevation of $\mathrm{NO}$ gave pro-inflammatory mediator that induced inflammation which led to an alteration of the vascular homeostasis [42]. Also, there was fibrosis in the portal area which demonstrated by Masson's trichrome stain and appeared in the form of increased collagen fibers in the portal areas. Gordon and sweets silver stain showed increased in the condensation of fine reticular fibers around the central vein and around the elements of the portal tract. Fibrosis explained by some authors who suggested that in chronic inflammation, hepatic stellate cells lost their lipid and vitamin A storage capability and differentiated into cells with characteristics of myofibroblasts. These cells appeared to play a role in hepatic fibrogenesis [38]. Also, the fibrosis pointed towards generally irreversible hepatic damage and mentioned that the major source of excess collagen was the perisinusoidal stellate cells [43]. In addition, oxidative stress acted as a stimulus for fibrogenesis. Positive correlation between the hepatic levels of thiobarbituric acid reactive substances and collagen and negative relationship between reduced glutathione and collagen suggested a link between oxidative stress and fibrogenesis [44]. The inflammatory responses were known to participate in the collagen synthesis and accumulation [45]. The condensation of the reticulin framework was demonstrated within the parenchyma. It was valuable in diffrentiatiation bridging necrosis from bridging fibrosis by showing condensation of residual loosely aggregated reticulin fibers [46].

In the current study, electron microscopic findings revealed that plasma membrane appeared ill defined. The nuclei of some hepatocytes were small and irregular, with an increased their chromatin content, other nuclei appeared indentated with an irregular nuclear envelope or even appeared enlarged. Pseudo inclusion bodies appeared in some cells. The mitochondria became swollen and lost their matrix and cristae even ruptured. The ill defined plasma membrane was explained by a study that suggested that injury and inflammation led to hydropic degeneration of the hepatocytes producing cells with empty pale cytoplasm that subsequently ruptured and underwent to necrosis. Also, the hepatocytes with hyperchromatic nuclei were anaplastic cells in which the nuclearcytoplasmic ratio might approach 1:1 instead of the normal 1:4 or 1:6 [32]. Pseudo inclusion bodies explained that the intra nuclear inclusions were invagination of the cytoplasm into the cell nuclei. These inclusions seem to be specific changes related to regeneration rather than degeneration [47]. Also, these inclusions were due to accumulation of substances in the nuclear matrix which were not normally of nuclear origin. These inclusions were observed in many tissue including liver [48]. The mitochondrial damage explained by increased cytosolic $\mathrm{Ca} 2+$, increased reactive oxygen species (oxidative stress), oxygen deprivation and all types of injurious stimuli, including toxins of drugs [29] This mitochondrial damage resulted in the opening of conductance channel in the mitochondrial membrane which was known as the mitochondrial permeability transition. The latter led to the loss of mitochondrial membrane potential, resulting in activation of number of enzymes, with potentially had deleterious cellular effects $[49,50]$.

In this study, electron microscopic findings revealed that the rough endoplasmic reticulum dispersed and dilated. Also, the smooth endoplasmic reticulum dilated. The glycogen content seemed to decrease while numerous lysosomes and lipid droplets were seen. Phagosomes, autophagic vacuoles, myelin figures or lamellar bodies appeared within cytoplasm of the citalopram treated mothers. Dilatation of the smooth endoplasmic reticulum was explained by a study that described the effect of drugs on the ultrastructure of the liver by that the liver responded on exposure to drug or toxin by proliferation and dilatation of the smooth endoplasmic reticulum [51]. The glycogen depletion in the citalopram treated mothers and their offspring could most probably be due to hepatocellular dysfunction resulting from hepatocellular injury. This explanation was confirmed by some authors who stated that reduction in the oxygen supply to cells led to decrease of oxidative phosphorylation and decrease in cellular ATP and increase in AMP. 
These changes stimulated phosphofructokinase and phosphorylase activities, leading to an increased rate of anaerobic glycolysis [43]. In this study, the presence of autophagic vacuoles with numerous whorls of membranes (myelin figures or lamellar bodies) were observed in the liver of citalopram treated mothers which was indicative to cellular injury. They were explained by the intracellular organelles and portions of cytosol were first sequestrated within an autophagic vacuole which was postulated to be formed from ribosome-free regions of the endoplasmic reticulum. The vacuole fused with lysosomes to form an autophagolysosome, in which the lysosomal enzymes digested the cellular components [32]. The presence of melyin-like figures were attributed to the inhibition of dihydroorotate dehydrogenase which located in the inner mitochondrial membrane [52,53]. Also, the selective resistance to lysosomal degradation within the autophagic vacuole results in the formation of membrane lamella [54]. In this study, von Kuppfer cells in the citalopram treated mother were apparently increased in numbers and showed phagosomes and vacuolation of their cytoplasm, these results were supported by study that revealed that citalopram administration by pregnant rats increased significantly von Kupffer cells and lymphocytes in the fetuses of the group who received citalopram at a dose of $20 \mathrm{mg} / \mathrm{kg} /$ day during gestation [5].

\section{References}

1- MORI M., MURATA Y., MATSUO A., et al.: Chronic treatment with the 5-HT1A receptor partial agonist tandospirone increases hippocampal neurogenesis. Neurol. Ther., 3: 67-77, 2014.

2- WIEGNER L., HANGE D., BJaORKELUND C. and AHLBORG G.: Prevalence of perceived stress and associations to symptoms of exhaustion, depression and anxiety in a working age population seeking primary care-an observational study. B.M.C. Fam. Pract., 16: 1-8, 2015.

3- LARSEN E.R., DAMKIER P., PEDERSEN L.H., FENGER-GRON J. and MIKKELSEN R.L.: Use of Psychotropic Drugs during Pregnancy and Breast-Feeding. Acta Psychiatr. Scand. Suppl., 132 (445): 1-28, 2015.

4- ARA I. and BANO S.: Citalopram decreases tryptophan 2, 3-dioxygenase activity and brain 5-HT turnover in swim stressed rats. Pharmacological Reports, 64 (3): 55866, 2012.

5- MOHAMMADI Z., AZARNIA M., MIRABOLGHASEMI G., SHIRAVI A. and MOHAMMADI Z.: Histological changes in the liver of fetuses of pregnant rats following citalopram administration. Indian J. Pharmacol., 45 (5): 517-21, 2013

6- PATRICK G.L.: “An Introduction to Medicinal Chemistry". 5 th ed. Oxford University Press. United Kingdom, p. 136, 2013.
7- LINLING C., QIANG Y., HAO Y., MICHAEL P.H. and CYNTHIA J.U.: Involvement of Natural Killer T Cells in Halothane-Induced Liver Injury in Mice.Biochem. Pharmacol., 80 (2): 255-61, 2010.

8- VOICAN C.S., NAVEAU S. and PERLEMUTER G.: Antidepressant-Induced Liver Injury: A Review for Clinicians. Am. J. Psychiatry, 171: 404-15, 2014.

9- FARTHING K., FERRILL M.G. and GENERALY G.A.: Drug Facts and Comparison. United States of America: Wolters Kluwer Health, p. 627, 2007.

10- MACIAG D., COPPINGER D. and PAUL I.A.: Evidence that the deficit in sexual behavior in adult rats neonatally exposed to citalopram is a consequence of 5-HT 1 receptor stimulation during development. Brain Res., 1125: 171$5,2006$.

11- KELLEMAN R.D. and BOPE E.T.: "Conn's Current Therapy 2015". 1 st ed. Elsevier Saunders. Philadelphia, p. $295,2015$.

12- PAGET G.C. and BARNES J.M.: "Toxicity in Evaluation of the Drug Activities". Pharmacometrics. Vol. I edited by: Laurence, D. R. and Bacharach, A.L., Academic Press, London, New York, pp. 1-13, 1964.

13- MARK A., SUN Z., WARREN D., LONZE B. and KNABEL M.: Stem cell mobilization is life saving in an animal model of acute liver failure. Ann. Surg. J., 252 (4): 5916, 2010.

14- MOULD R.F.: "Introductory Medical Statistics". 3 rd ed. Institue of physics publishing. Bristol, Philadelphia, pp. 18-27, 1998

15- KIERNAN J.: " Histological and Histochemical Methods: Theory and Practice ". 3 rd ed.Arnold Publisher. London, New York, New Delhi. pp. 111-62, 2001.

16- DRURY R.A. and WALLINGTON E.A.: "Carleton's Histological Technique”. 7 th ed., Oxford University Press. New York, Toronto. pp. 137-45, 1980.

17- SUVARANA S.K., LAYTON C. and BANCROFT J.D.: "Bancroft's Theory and Practice of Histological Techniques". 7 th ed. Churchill Livingstone. China, pp. 208-10, 2013

18- BANCROFT J.D. and GAMBLE M.N.: "Theory and Practice Histology Techniques". 6 th ed. Churchill- Livingstone. London. pp. 340-8, 2008.

19- WALTHALL K., CAPPON G.D., HURTT M.E. and ZOETIS T.: Postnatal development of the gasterointestinal system: A species comparison. Birth Defect. Res. B. Dev. Rerod. Toxicol., 74: 132-56, 2005.

20- JAIWSWAL A., SINHA D.N. and SINGH A.K.: A study on histology of fetal liver. Nation. J. Clin. Anat., 4 (1): 26-9, 2015.

21- ALEXANDER B., GUZAIL M.A. and FOSTER C.S.: Morphological Changes during Hepatocellular Maturity in Neonatal Rats. The Anat. Record., 248: 104-9, 1997.

22- SCHIFF E.R., SORRELL M.F. and MADDREY W.C.: "Schiff's Disease of the Liver". 10 th ed. Lippincott Williams \& Wilkins. Philadelphia. pp. 31-5, 2007.

23- SHARP P.E. and VILLANO J.S.: "The Laboratory rats". 2nd ed. CRC Press. New York, pp. 23-6, 2012. 
24- FERRAJOLO C., SCAVONE C., DONATI M., BORTOLAMI O., STOPPA G., MOTOLA D., et al.: Antidepressant-induced Acute Liver Injury: A case-Control Study in an Italian Inpatient Population. Drug Safety, 41 (1): 95-102, 2018

25- KELLNER M., PORSERYD T., PORSCH-HÄLLSTRÖM I., BORG B., ROUFIDOU C. and OLSÉN K.H.: Developmental exposure to the SSRI citalopram causes longlasting behavioural effects in the three-spined stickleback (Gasterosteus aculeatus). Ecotoxicol. J., 27 (1): 12-22, 2018.

26- ABDELMAJEED N.A.: Oxidative Tissue Damage Induced by Citalopram in Rat Different organ. Research Journal of Medicine and Medical Science, 4 (2): 580-6, 2009.

27- PARK S.H. and ISHINO R.: Liver injury associated with antidepressants. Current Drug Safety, 8 (3): 207-23, 2013.

28- VANLANGENAKKER N.: Molecular mechanisms and pathophysiology of necrotic cell death. Curr. Mol. Med., 8: 207, 2008.

29- NEWMEYER D.D. and FERGUSON-MILLER S.: Mitochondria: Releasing power for life and unleashing the machineries of death. Cell, 112: 481, 2003.

30- HABIB M., TAHIR M., LONE K. and SAMI W.: Study to Evaluate Hepatotoxic Characterizations Induced Through Ethanol in Albino Rats Musculus. J. College. Phys. Surg., 21 (10): 642-3, 2011.

31- CORCORAN G.B., FIX L., JONES D.P., MOSLEN M.T., NICOTERA P., OBERHAMMER F.A. and BUTTYAN R.: Apoptosis: Molecular control point in toxicity. Toxicol. Appl. Pharmacol., 128: 169-81, 1994.

32- KUMAR V., ABBAS A.K. and ASTER J.C.: "Robbins Basic pathology". 7 th ed. Saunders. Philadelphia, USA. pp. 8-16 and 612, 2013.

33- RUTHERFORD A. and CHUNG R.: Acute liver failure: Mechanisms of hepatocyte injury and regeneration. Semin Liver Dis., 28: 167-74, 2008.

34- COX N. and MOHANTY S.: Acute liver failure. Hosp. Phys., 5 (45): 7-15, 2009.

35- TAKI-ELDIN A., ZHOU L., XIE H.Y. and ZHENG S.S. Liver Regeneration after Liver Transplantation. Eur. Surg. Res., 48: 139-53, 2012.

36- ADHVARYU M.R., REDDY N. and PARABIA M.H.: Effects of four indian medicinal herbs on isoniazid and pyrazinamide-induced hepatic injury and immunosuppression in guinea pigs. World J. Gastroenterol., 13: 3199205, 2007.

37- ARMSTRONG C: ACOG Guidelines on Psychiatric Medication Use during Pregnancy and Lactation. Am. Fam. Physician, 78 (6): 772-8, 2008.

38- ROSS M.H. and PAWLINA W.: "Histology: A Text and Atlas with Correlated Cell and Molecular Biology". 7 th ed. Lippincott Williams \& Wilkins Philadelphia, pp. 62939, 2006.

39- PAL R., VAIPHEI K., SIKANDER A., SINGH K. and RANA S.V.: Effect of garlic on isoniazid and rifampicininduced hepatic injury in rats. World J. Gastroenterol., 12 (4): 636-9, 2006.
40- TANDON V.R., KHAJURIA V., KAPOOR B., KOUR D. and GUPTA S.: Hepatoprotective activity of Vitex negundo leaf extract against anti-tubercular drugs induced hepatotoxicity. Fitoterapia, 79: 533-8, 2008.

41- PORAYETTE P. and PAULSON R.F.: BMP4/Smad5 dependent stress erythropoiesis is required for the expansion of erythroid progenitors during fetal development. Dev. Biol., 317 (1): 24-35, 2008.

42- SHARMA J.N., AL-OMRAN A. and PARVATHY S.S. Role of nitric oxide in inflammatory diseases. Inflamma. Pharmacol., 15: 252-9, 2007.

43- KUMAR K.M., ABBAS A.K., FAUSTO N. and ASTER J.C.: Cellular responses to stress and toxic insults: Adaptation, Injury, and Death. In: Robbins and Cortan Pathological Basis of Disease. 8 th ed., Saunders Elsevier, Philadelphia, pp. 13-22 and 880-6, 2009.

44- DEVI S.L., VISWANATHAN P. and ANURADHA C.V.: Regression of liver fibrosis by taurine in rats fed alcohol: Effects on collagen accumulation, selected cytokines and stellate cell activation. Euro. J. Pharmacol., 647: 161-70, 2010.

45- LEE U.E. and FRIEDMAN S.L.: Mechanisms of hepatic fibrogenesis. Pract. Res. Clin. Gastroenterol., 25: 195206, 2011.

46- CHAN A.W.H., QUAGLIA A., HAUGK B. and BURT A.: "Atlas of Liver Pathology" 1 st ed.Spring. New York, Heidelberg. Dorodrecht. London, p. 12, 2014.

47- JOHANNESSEN J.V.: Electron Microscopy in Human Medicine. Volume 8. The liver. Mc Grraw-Hill International Book Campany. New York. St Louis. San Francisco, pp. 128-32, 1979

48- THAKUR P., LAMOKE F., CHAFFIN J.M., BARTOLI M., LEE J.R. and DUNCAN M.B.: Dysplastic Hepatocytes Develop Nuclear Inclusions in a Mouse Model of Viral Hepatitis. PLoS One. J., 9 (6): e 99872, 2014.

49- BERNARDI P.: The mitochondrial permeability transition from in vitro artifact to disease target. FEBS J., 273: 2077, 2006.

50- CHOWDHURY 2006 CHOWDHURY A., SANTRA A., BHATTACHARJEE K., GHATAK S., SAHA D.R. and DHALI G.K.: Mitochondrial oxidative stress and permeability transition in isoniazid and rifampicin induced liver injury in mice. J. Hepatol., 45: 117-26, 2006.

51- HOLT M. and JU C.: Mechanisms of drug-induced liver injury. AAPSI; 8: E48-E54, 2006.

52- JAISWAL A., SINHA D.N. and SINGH A.K.: A study on histology of fetal liver Nation. J. Clin. Anat., 4 (1): 26-9, 2015.

53- SCHMITZ G. and MÜLLER G.: Structure and function of lamellar bodies, lipid-protein complexes involved in storage and secretion of cellular lipids. J. Lipid. Res., 32: 1539-70, 1991.

54- HARIRI M., MILLANE G., GUIMOND M.P., GUAY G., DENNIS J.W. and NABI I.R.: Biogenesis of Multilamellar Bodies via Autophagy. Molecular Biology of the Cel, 11: 255-68, 2000. 


\section{تآثيرتناول السيتالوبرام على كبد حوامل

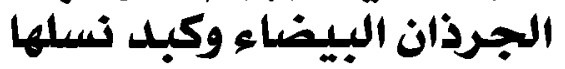

الخذفية: الإكتئاب والقلق من المشاكل الصحية الثائعة ويعد السيتالويرام من آول طريق علاج الإكتئاب وذلك لآته له قدره عالية وإنتقائية

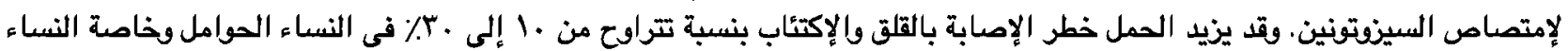

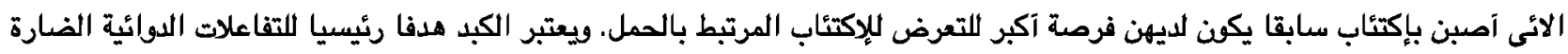
لآنه موقع التحل الكيميائى والتمثيل الغذائى للآدوية.

الهدف من البحث: إن الهدف من الدراسة هو تقييم تآثير إعطاء السيتالوبرام على كبد آنثى الجرذان اليضاء الحوامل وكبد نسلها.

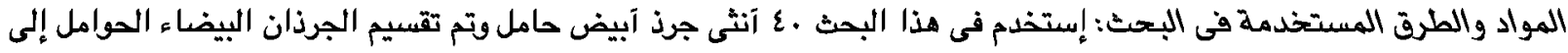

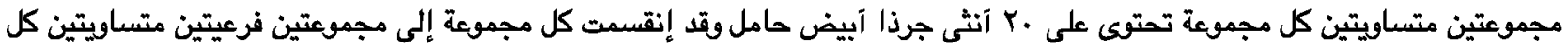

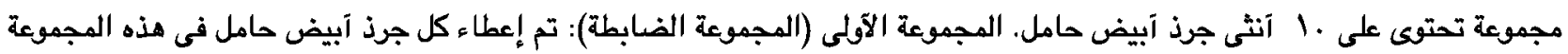

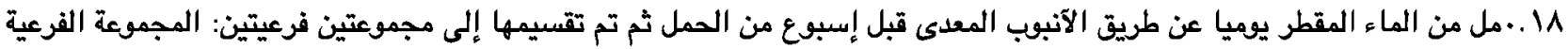

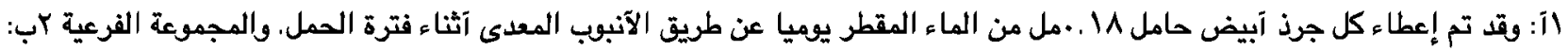

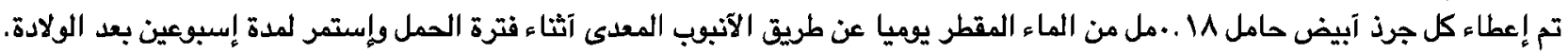

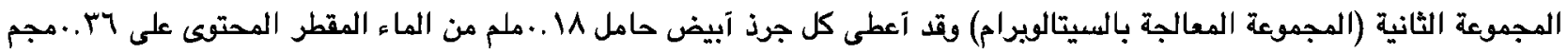

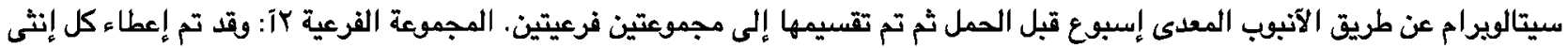

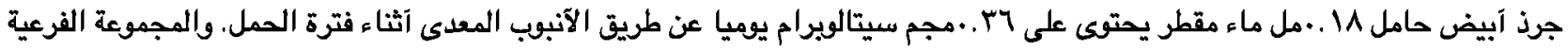

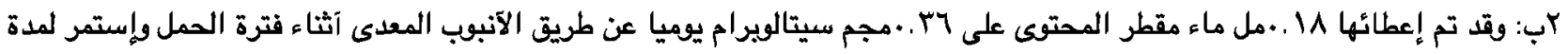

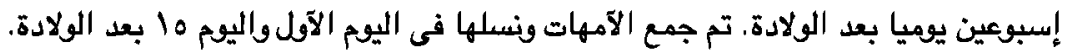

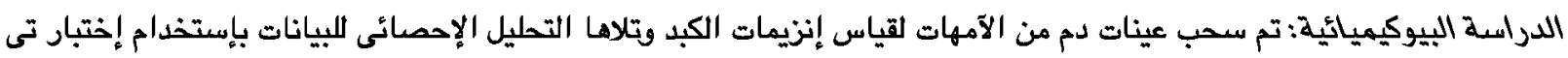

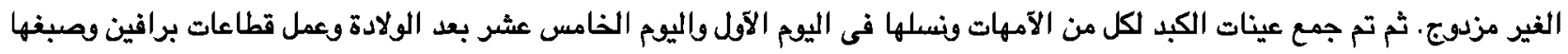

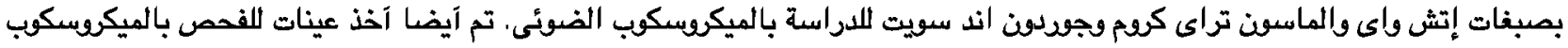

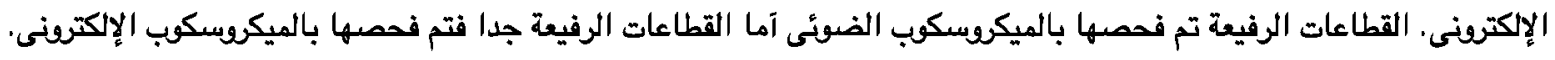
النتائج: إن إعطاء السيتالوبرام آدى إلى إرتفاع بالغ في إنزيمات كبد آمهات الجرذان البيضاء. آيضا السيتالوبرام آدى إلى فساد وموت

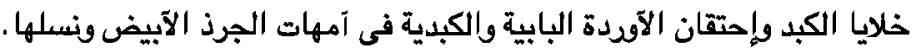
الخلاصة: آدى تناول السيتالوبرام إلى حدوث تغييرات إنتكاسية فى كبد آمهات الجرذان البيضاءوكبد نسلها عندما آعطى قبل وآثناء الحمل 